MARTínEZ NAVAS, I., «Ordenanzas de la villa de Navarrete (siglos XIV - XVI)», REDUR 16, diciembre 2018, págs. 25-60. ISSN 1695-078X. doi: 10.18172/redur.4231

\title{
ORDENANZAS DE LA VILLA DE NAVARRETE (SIGLOS XIV - XVI)
}

\author{
Isabel MARTÍNEZ NAVAS \\ PROFESORA Titular DE Historia DEL DERECHO Y DE LAS InSTITUCIONES \\ UNIVERSIDAD DE LA RIOJA
}

SumARiO: I. INTRODUCCIÓN. II. EL CONCEJO DE NAVARRETE A LA LUZ DE SUS «ORDENANZAS ANTIGUAS». III. LAS «ORDENANZAS PARA EL BUEN GOBIERNO DE LA VILLA DE 1564». IV. APÉNDICE DOCUMENTAL.

RESUMEN: Navarrete fue una villa de señorio desde el último tercio del siglo XIV y hasta comienzos del siglo XIX. Las noticias más antiguas acerca de la organización de su gobierno local corresponden a los primeros años del siglo XV y proceden de un traslado de diferentes ordenanzas formalizado en 1584. De éstas y de un extenso cuerpo normativo concluido unos años antes me ocupo en el presente trabajo.

Palabras Clave: Ordenanzas municipales, Navarrete, Administración local medieval y moderna, Derecho local medieval y moderno.

\section{LOCAL CODES AND ORDINANCES OF THE TOWN OF NAVARRETE $\left(14^{\mathrm{TH}}-16^{\mathrm{TH}}\right.$ CENTURY)}

ABSTRACT: the town of Navarrete was under the rule of a lord from the last third of the fourteenth century until the beginning of the nineteenth century. The oldest records of its local governance organisation are from the first years of the fifteenth century, found on a document dated 1584, which comprises several ordinances. This work is an analysis of these different regulatory frameworks.

KEYWORDS: municipal ordinances, Navarrete, Medieval and Modern local administration, Medieval and Modern local law

\section{Introducción}

Navarrete recibió, en 1195, como derecho propio, el Fuero de Logroño ${ }^{1}$. En el siglo XIV la villa experimentó un notable incremento de su ámbito de influencia merced a la

\footnotetext{
${ }^{1}$ Martínez DíEz, Gonzalo, «Los Fueros de La Rioja», Anuario de Historia del Derecho Español, 49 (1979), pp. 327 454; Hergueta, Narciso, «El Fuero de Logroño. Su extensión a otras poblaciones», Boletín de la Real Academia de la Historia, 50 (1907), pp. 321-322.
} 
adquisición de las poblaciones vecinas de Fuenmayor, Hornos, Sotés y Daroca ${ }^{2}$. Por este tiempo y hasta avanzado el siglo XIX se convirtió en villa señorial, ligada, en primer lugar y por corto espacio de tiempo, al linaje de los Ramírez de Arellano $^{3}$ y, poco después, por donación de Juan I, al de los Manrique4.

De este tiempo proceden las noticias más antiguas sobre organización de la villa señorial. Unas ordenanzas, conservadas en la Sección Judicial del Archivo Histórico Provincial de La Rioja ${ }^{5}$, que corresponden a las catalogadas en un antiguo inventario del siglo XVIII del Archivo Municipal de Navarrete como «Ordenanzas hechas en el año de 1582» y «Ordenanzas para el buen gobierno de esta villa. Año de $1564{ }^{6}$.

De unas y otras me ocupo en estas páginas. Las primeras tienen el valor de contener los testimonios más antiguos de ordenación de la vida local en la villa sujeta al dominio de los Manrique de Lara. Las segundas, el de ser un cuerpo de ordenanzas muy extenso -más de un centenar de capítulos- en el que se abordan aspectos tocantes al gobierno de la villa, junto a otros de policía urbana y, fundamentalmente, atentos a la ordenación y salvaguarda del campo y las actividades agropecuarias.

Presto atención, en primer término, a las ordenanzas más antiguas, que -como se verá- nos permiten obtener noticias relevantes acerca del gobierno de la villa muy anteriores a las documentadas hasta ahora y que corrigen, en buena medida, la imagen que se nos ha trasladado de una localidad que habría gozado de un relevante nivel de autonomía hasta finales del siglo XV. En el siguiente apartado me refiero a la gestación y, brevemente, al contenido de las extensas Ordenanzas de 1564, cuyo texto íntegro se transcribe en el cuarto y último apartado de este trabajo ${ }^{7}$.

\footnotetext{
2 Martínez Sopena, Pascual, «Logroño y las villas riojanas en los siglos XII-XIV», en SeSma MúÑoz, José Ángel (coord.), Historia de la Ciudad de Logroño, Logroño, 1995, vol. II, pp. 279-322.

3 En 1369 Enrique II otorgó la villa de Navarrete a Juan Ramírez de Arellano. Poco después se reintegró al realengo por permuta con el castillo y la villa de Aguilar de Inestrillas. Sobre su vinculación a los Ramírez de Arellano, GonzÁlez Crespo, Esther, «Los Arellano y el señorío de los Cameros en la Baja Edad Media», En la España medieval, 2 (1982), pp. 395-410.

4 Montero Tejada, Rosa María «Los señoríos de los Manrique en la baja Edad Media», en Espacio, Tiempo y Forma, Serie III, Historia Medieval, t. 7, 1994, pp. 205-258. La misma autora, sobre el linaje de los señores de Navarrete, Nobleza y sociedad en Castilla. El linaje Manrique (siglos XIV-XVI), Madrid, 1996.

${ }^{5}$ Archivo Histórico Provincial de La Rioja [AHPLR], Sección Judicial, caja 89/3.

${ }^{6}$ Archivo Municipal de Navarrete [AMN], Fondo Municipal, caja 82, «Ymbentario de todos los papeles que tiene el Archiuo general de esta Villa de Navarrete, que se hizo siendo rex $^{0}$ D. Jacinto de Lariz y Moreda, el año de Setecientos y veinte, con asistencia de los Sres. D. Joseph Antolinez y D. Joseph Diez Heredia, beneciados de esta Yglesia». Las ordenanzas se registran, respectivamente, como «Núm. 68. Letra V. » y «Núm. 69. Letra V».

7 En la transcripción de las Ordenanzas de 1564, que se incluye en el apartado IV, se ha respetado la grafía, puntuación y acentuación originales del texto manuscrito de 1607 conservado en el AHPLR, en tanto se ha procurado adaptar el texto a las reglas de puntuación y acentuación actuales, procediéndose además al desarrollo de las abreviaturas, a la eliminación de las consonantes dobles y a la utilización de mayúsculas y minúsculas de forma que se facilite la lectura y comprensión de los fragmentos de las citadas Ordenanzas de 1564 o de las otras normas más antiguas que se insertan en los apartados II y III de este trabajo.
} 


\section{El concejo de Navarrete a la luz de sus «Ordenanzas Antiguas»}

Las «Ordenanzas hechas en el año 1582», a las que se refiere el registro inserto en el Inventario de 1720 del Archivo navarretense, podrían ser las contenidas en un ejemplar manuscrito conservado en el Archivo Histórico Provincial de La Rioja. El documento precedido de la anotación «traslado de otras que llaman "hordenanças que sacó Santa Coloma"»- es un traslado extendido por este escribano, el 14 de agosto de 1582, a instancias del duque de Nájera y que contiene la transcripción de diferentes ordenanzas de los primeros años del siglo XV y la noticia de un ordenamiento anterior, fechado en 13848 .

El testimonio más antiguo procede, así, de apenas tres años después de que Diego Gómez Manrique hubiese incorporado la villa de Navarrete a sus dominios ${ }^{9} \mathrm{y}$ corresponde a un denominado «cuaderno y posturas» que el alcalde y jurados de la villa habrían presentado al duque con el fin de que lo mandase cumplir y guardar. El tenor literal de esas normas habría sido cuidadosamente recogido por el escribano Pascual Sánchez, formando -a decir del mismo- un «Libro de pergamino en treinta y seis planas sin ésta». Ese, al parecer, extenso ordenamiento fue aprobado por el concejo navarretense el 30 de mayo de 1384, habiéndose reunido «a concejo pregonado de antenoche, según que lo habemos de uso y de costumbre en el dicho lugar». Lamentablemente, el pormenor de esas normas no forma parte de las reunidas por Santa Coloma, quien se limitó a dar cuenta de su existencia y a incorporar la cabeza y pie del documento que obraba en su poder:

... y asimismo doy fe que en el dicho cuaderno -se refiere a un cuaderno que dice está en su poder, escrito en cuarto de pliego, de letra antigua, de muchas hojas- y en el proceso de él, en la primera hoja, está puesta y hecho que parece que, al principio de él, de posturas e cosas que estando en concejo hacían y ordenaban los que en él estaban. Y tras aquella cabeza y autos, otras muchas posturas y capítulos en la dicha primera hoja y en otras siguientes que fueron a ésta y al fin de él está el día en que parece se hicieron las dichas posturas y el año, que parece fue en el año de mil y trescientos y ochenta y cuatro, que su tenor, de la cabeza de cuaderno y del fin de estas dichas posturas y capítulos y de las dichas ordenanzas es el siguiente:.. ${ }^{10}$.

\footnotetext{
${ }^{8}$ La provisión, a pedimento del duque, para sacar un traslado de las Ordenanzas Antiguas, año de 1582, en AMN, Fondo Municipal, caja 82, f. 60r. El requerimiento de disponer el documento se lo trasladó el mayordomo de las rentas del duque de Nájera y vecino de la villa, Fernando de Nalda Marroquín, remitiéndole a tal efecto la correspondiente provisión real y centrando el contenido de lo que se requería en los siguientes términos: «...le diese un traslado signado y en pública forma de las ordenanzas antiguas que en mi poder estaban, y autos hechos en el año de mil y cuatrocientos y once, y mil y cuatrocientos y cuatro, y mil y cuatrocientos y nueve, y mil y cuatrocientos y ocho, que él estaba presto a pagar los derechos debido», AHPLR, Sección Judicial, caja $89 / 3$.

${ }^{9} \mathrm{El} 1^{\circ}$ de diciembre de 1379 Juan I donó a Diego Gómez Manrique la villa de Navarrete con sus aldeas, vasallos, rentas y derechos, confiriéndole además la justicia civil y criminal. La merced fue confirmada el 2 de febrero de 1380, RAH, Colección Salazar y Castro, M-1, fol. 186, cit. por MonTERo TejADA, Rosa María, «Los señoríos de los Manrique...», cit., p. 208.

${ }^{10}$ El ejemplar manuscrito conservado en el AHPLR incluye una anotación al margen del texto -que se extiende a toda la transcripción de la cabeza y pie del documento- en la que se indica que «está sacado de su oficio sin pedírselo».
} 
Del fragmento transcrito por Santa Coloma se desprende además que la finalidad por la que fue dispuesto el cuaderno y postura aprobado en 1384 era la «guarda, defendimiento y mejoramiento del concejo de la villa y de sus aldeas. Y de todos los vecinos, moradores y habitantes de la dicha villa y sus aldeas, así de los presentes como de los que vendrán de aquí adelante para siempre».

Sí conocemos el tenor literal de las disposiciones correspondientes a los primeros años del siglo XV que fueron reunidas por el escribano navarretense Santa Coloma. Se trata de varios ordenamientos, de desigual extensión y alcance, fechados entre $1404 \mathrm{y}$ 1411. Llegan hasta nosotros a partir de un traslado de este último año que el concejo dispuso que se hiciese al objeto de preservar las ordenanzas:

En la villa de Navarrete, martes diez días del mes de febrero, año de nacimiento de nuestro señor Jesucristo de mil y cuatrocientos y once, en la cámara del concejo de la dicha villa [...] presentaron e hicieron leer por mí, el dicho escribano -Juan García, "escribano de nuestro señor el rey y su notario público en la su Corte y en todos los sus reinos"- una ordenanzas del dicho señor adelantado [Pero Manrique], escrita en un cuaderno de papel en cuatro hojas de cuarto de pliego y dos planas de ese mismo marco, firmada del nombre del dicho señor adelantado y sellada en fin de ella con un sello de cera bermeja en las espaldas [...].

Y el dicho cuaderno leído por mí el dicho escribano, los dichos regidores y el dicho Juan Martínez Valgañón, alcalde del dicho año pasado, por servicio del dicho señor y porque lo por él ordenado fuese cumplido y guardado de ahora y de aquí adelante, dijeron que ellos en voz y en nombre del dicho concejo habían recelo por cuanto la dicha ordenanza era escrita en papel que se podría perder por tiempo muchas ocasiones, las primeras porque el dicho papel se mojaría, o dañaría, o quemaría en manera que no podría hacerse, y por ende que pedían y pidieron, de parte del señor adelantado, así como sus oficiales, y otrosí del dicho concejo, al dicho alcalde que mandase a mí el dicho escribano que hiciese o mandase hacer un traslado, dos, o más de la dicha ordenanza, poniendo en ello su decreto, en manera que hiciese fe a tan bien y a tan cumplidamente como por el dicho cuaderno de ordenamiento se contenía a doquier que pareciese y de cómo se lo decían y requerían, pidieron a mí el dicho escribano que les diese testimonio.

Y luego, el dicho alcalde dijo que venía el dicho ordenamiento escrito en papel, como dicho es de suso, no vicioso, ni roto, ni raído, ni dañado, ni cancelado, ni en alguna parte sospechoso, e que, por ende, mandaba y mandó, y daba y dio licencia y autoridad a mí el dicho escribano que hiciese, o mandase hacer, un traslado, o dos, o más del dicho cuaderno de ordenanza, y que allí ponía y puso en él su decreto...

Las prescripciones que contienen -procedentes de los años 1404, 1408 y 1409, a las que se añaden después otras dispuestas en el propio año 1411- no están numeradas en ninguno de los textos normativos recogidos y presentan dificultades, en algunos casos, para su lectura, debidas, fundamentalmente, al deterioro del soporte en el que se nos muestran, esto es, el manuscrito del traslado efectuado en 1582.

Los más extensos y, sin duda, más relevantes de estos ordenamientos son los dados, en 1404 y 1409, por Pero Manrique, adelantado mayor del reino de León, señor de 
Amusco y duque de Nájera ${ }^{11}$. Constan de catorce capítulos, respectivamente, en los que se abordan cuatro grandes temas: por una parte, el grueso de las prescripciones en las Ordenanzas de 1404 -y, aunque en menor medida, también de las de 1409-, se refiere a diversos extremos relativos al gobierno de la villa. De otro lado, en ambos casos se dedican algunos de los capítulos a cuestiones tocantes al desarrollo de los pleitos y el abono de las costas judiciales. Asimismo, en ambos textos normativos está presente, en mayor o menor medida, la obligación de abono del servicio por parte de los vecinos de Navarrete y diversas cuestiones relativas a la hacienda concejil.

Por lo que se refiere a la organización del gobierno de la villa de Navarrete, algunos estudios sobre la organización concejil en este período en La Rioja refieren la existencia en Navarrete, antes de la mitad del siglo XIV, de alcaldes y jurados que celebraban sesiones del concejo en el claustro de la Iglesia de Santa María, con la asistencia además de vecinos de la villa ${ }^{12}$, indicando que esta organización se habría mantenido en los siguientes años y señalando que no es posible conocer -por falta de documentación- la incidencia en Navarrete de la reforma municipal introducida por Alfonso XI y que no puede documentarse la presencia de regidores en esta villa riojana hasta la década de los años veinte del siglo $\mathrm{XV}^{13}$.

En este sentido, las Ordenanzas antiguas aquí analizadas resultan bien esclarecedoras. Las Ordenanzas de 1 de enero de 1404 muestran con claridad la injerencia temprana del señor en el gobierno de la villa y permiten conocer la estructura de administración establecida por Pero Manrique para la misma. Un gobierno local que se asienta sobre la existencia de un alcalde y dos regidores en los que se resumen todas las competencias del concejo:

Otrosí, es mi merced que sean dos regidores, los cuales con el mi alcalde que ahora es, o fuer de aquí adelante, vean y rijan todas las cosas del Concejo, en tal manera que sea cumplidera a mi servicio y al provecho del lugar, y que con estos regidores y alcalde que no se ajunten otros algunos, ni hagan ayuntamiento alguno de concejo en todo el año más, antes que esto que puedan hacer todas las cosas que podría hacer el concejo siendo ayuntado todavía... ${ }^{14}$.

Dos regidores - «es mi merced que no sean más de dos regidores», reitera más adelante [cap.5]- y un alcalde que eran designados por el señor cada año -«que les duren

\footnotetext{
11 AHPLR, Sección Judicial, caja 89/3, «Traslado de otras que llaman Ordenanzas que sacó Santa Coloma», Ordenanzas de 1404; Ordenanzas de 1409. Citadas, en adelante, como Ordenanzas antiguas. He numerado correlativamente los capítulos -que no lo están en el original- para facilitar la referencia a los mismos.

12 Goicolea Julián, Francisco Javier, El gobierno urbano en La Rioja en época medieval e inicios de la Edad Moderna (s. XIII-mediados del XVI), Logroño, Instituto de Estudios Riojanos, 2004. Del mismo autor, «Concejos urbanos en La Rioja Alta a fines del Medievo: aspectos institucionales y políticos», Historia, Instituciones, Documentos, 26 (1999), pp. 233-254 y, en particular, «Navarrete a finales de la Edad Media: Gobierno y sociedad en una villa riojana de señorío», Berceo, 136 (1999), pp. 59-86.

13 Goicolea Julián, Francisco Javier, «Navarrete a finales de la Edad Media...», cit., 61-62.

14 Ordenanzas antiguas, cap. 2.
} 
los oficios un año y no más, de año nuevo en año nuevo» [cap. 3]- y que percibían de salario trescientos y seiscientos maravedís, respectivamente [caps. 5 y 6$]^{15}$.

Junto al alcalde y regidores, las Ordenanzas de 1404 refieren la existencia de otros oficiales -merino, jurados y escribanos- atribuyendo su elección al propio señor o a los navarretenses ${ }^{16}$. Así, con carácter general, disponen que, no estando presente el señor en la villa, puedan escogerse los oficiales y enviar relación de los mismos para que después aquél los confirme ${ }^{17}$. Esta previsión se reitera después expresamente en relación al merino. Designado en ese momento aquel que debía desempeñar ese oficio ${ }^{18}$, se prevé que transcurrido un año sea sustituido por otro que nombraría el propio señor o sería escogido por los vecinos.

... que dure por un año y no más, y dende adelante que sea mudado otro en cada año, es escogido por vosotros yo no estando en el dicho lugar, y puesto por mí estando yo. Pero escogido por vosotros, que sea confirmado por mí19.

La previsión tocante a la designación del merino se completa con aquellas otras en las que se hace referencia al desempeño de su oficio de Merindad y se regulan las percepciones que le correspondía obtener, destinándose a este fin tres capítulos de las Ordenanzas de 1404:

15 Para el año 1404, los designados por Pero Manrique fueron Juan García, el mozo, como alcalde y Fernán Martínez Balgañón y Juan Fernández de Collado, como regidores, ibídem, caps. 5 y 6.

16 Sobre la estructura y organización de los concejos, Merchan Fenández, Carlos, Gobierno municipal y administración local en la España del Antiguo Régiemn, Madrid, ed. Tecnos, 1988. En particular, por lo que se refiere al entorno de nuestra villa, vid. DíEz DE DuRANA, Jose Ramón, «La reforma municipal de los Reyes Católicos y la consolidación de las oligarquías urbanas: el Capitulado vitoriano de 1476 y su extensión por el nordeste de la Corona de Castilla», en Actas del Congreso La Formación de Álava, Vitoria, 1986, tomo I, pp. 213237 y Vitoria a fines de la Edad Media (1428-1476). Vitoria, ed. Diputación Foral, 1984; MARTínEz NAVAS, Isabel, «Elecciones de oficios en la ciudad de Logroño en la Edad Moderna», Anuario de Historia del Derecho Español, 67 (1997), pp. 1249-1270 y Gobierno y administración de la ciudad de Logroño en el Antiguo Régimen, Madrid, INAP, 2001; Moya VALGAÑon, José «Los oficios concejiles en La Rioja hasta 1250», Berceo, 100 (1981), pp. 139-167.

17 Ordenanzas antiguas, cap. 4.

18 Se designó, para el año 1404, al hijo de Fernán Martínez Ballestero, ibídem, cap.9.

19 Ibídem, cap. 10. La previsión tocante a la designación del merino se completa con aquellas otras en las que se hace referencia al desempeño de su oficio de merindad y se regulan las percepciones que le correspondía obtener, destinándose a este fin tres capítulos de las Ordenanzas antiguas:

... Y es mi merced que lleve por el dicho oficio de merindad esto que se sigue: por el carcelaje del hombre labrador, seis mrs; y del hidalgo, o moro, o judío, doce mrs. Y este carcelaje que lo lleve si trasnochare, e si no trasnochare que lleve dos mrs más en cada. [cap. 9]

Otro si, que lleve el diezmo de todo lo que entregare, salvo ende de los mrs del rey, que lleve del millar treinta mrs, según el rey manda. Y la mayor entrega de los del rey que suba hasta ciento y ochenta mrs, según el rey manda. Y por el embargo que lleve dos mrs y dende sin embargo, dos mrs. [cap. 10]

Otro sí, es mi merced que el dicho merino que lleve las penas de traer las armas que a mí pertenecen [cap. 12] 
... Y es mi merced que lleve por el dicho oficio de merindad esto que se sigue: por el carcelaje del hombre labrador, seis mrs; y del hidalgo, o moro, o judío, doce mrs. Y este carcelaje que lo lleve si trasnochare, e si no trasnochare que lleve dos mrs más en cada. [cap. 9]

Otrosi, que lleve el diezmo de todo lo que entregare, salvo ende de los mrs del rey, que lleve del millar treinta mrs, según el rey manda. Y la mayor entrega de los del rey que suba hasta ciento y ochenta mrs, según el rey manda. Y por el embargo que lleve dos mrs y dende sin embargo, dos mrs. [cap. 10]

Otrosí, es mi merced que el dicho merino que lleve las penas de traer las armas que a mí pertenecen [cap. 12].

De otro lado, los jurados -cuyo número no aparece limitado en las ordenanzas ${ }^{20}$ serán siempre de elección de los navarretenses, que escogerán «aquellos que entendieren que cumplen a mi servicio y a provecho de la dicha villa y de su tierra» [cap. 11], en tanto los escribanos -en las Ordenanzas de 1404 se mencionan dos, uno que lo es del Ayuntamiento y otro por el que «es mi merced que pasen todos los pleitos de los juicios» [cap. 13]-, serán designados por el señor ${ }^{21}$.

A tenor de las Ordenanzas de 1404, la presencia del escribano del Concejo -que percibe de salario trescientos maravedís [cap. 17]- es imprescindible para la celebración de los Ayuntamientos ${ }^{22}$, debiendo estar presente también en los derramamientos y otros actos del Concejo:

... que tengan consigo en cada ayuntamiento a Pascual Sánchez, escribano público que les yo di, u otro escribano alguno les yo diere de aquí adelante. Y que sin él no puedan hacer ayuntamiento alguno, ni derramamiento, ni otro acto alguno que sea, porque yo pueda ser cierto por el dicho escribano de todas las cosas que se hicieren o fueren tratadas por ellos en todo su tiempo que les duraren los oficios [cap. 2].

Al escribano le corresponde documentar la labor realizada por el alcalde y los regidores, debiendo ser el escribano del Concejo y no otro cualquiera -«so pena de la mí merced y de seiscientos mrs para la mí cámara a cada uno de vos»- el que redacte las escrituras del Concejo tocantes a derramamientos «y otras cosas que pasaren en cámara por el alcalde y regidores» [cap. 14]. Era asimismo el escribano el encargado de elaborar la relación de todo lo actuado en el año de mandato del alcalde y los regidores, que se hacía llegar al señor:

\footnotetext{
20 Por lo que se refiere a los jurados, las Ordenanzas antiguas refieren la presencia de tres, a los que se asigna una retribución adicional al salario que les abona el concejo, en atención a la misión que se encomienda a uno de ellos de recaudar anualmente el servicio debido al señor y a la colaboración de los otros dos: « [...] e mando que el Jurado cogedor del mi pedido, haya del dicho mi pedido doscientos maravedís, pero que los otros Jurados, sus compañeros, le han de relevar de las otras, por razón de la cosecha del mi pedido, que ellos le han de ayudar a entregar. Por ende, mando que todos tres los Jurados hjayan los dichos doscientos maravedís del dicho mi pedido, demás de lo que han de salario del Concejo», Ordenanzas antiguas, cap. 26.

${ }^{21}$ El escribano del Concejo es en ese momento Pascual Sánchez, en tanto el designado para registrar todos los pleitos en la villa fue Pero Martínez, Ordenanzas antiguas, caps. 2 y 13.

22 Vid. Corral García, Esteban, El escribano de concejo en la Corona de Castilla, Burgos, 1987.
} 
Otrosí, que el alcalde y regidores [...] que antes quince días que se acaben los oficios, que sean tenidos, si yo no fuere en el dicho lugar, de me enviar relación cierta hecha, o mandada hacer, por el dicho escribano, señalada de él y de los dichos oficiales, de todas las cosas que acaecieren en aquel año, para que la yo pueda ver, o mandar ver, y si a este tiempo algún mi teniente lugar a estar en el dicho lugar con mi poderío para ello, que se lo muestren a él [cap. 3].

Por su parte, las ordenanzas de 1409 contienen alguna prescripción más relativa al funcionamiento del Concejo. Disponen, así, que alcalde, regidores y escribano «se ayunten en cada tres días en la semana, martes y jueves y sábado y que este ayuntamiento que lo hagan en la Iglesia, a hora de la prima, en acabándose las misas», o que lo hagan también en otros días siendo llamados porque fuere menester juntarse. Establecen, asimismo, que, en caso de ausencia de alguno de ellos, «que puedan hacer los otros sin él y ordenar todas las cosas, así como si fuere presente», sancionándose a quien no hubiese asistido con sesenta maravedís "para los otros que fueren» y previéndose, como excepción, la ausencia del alcalde en el supuesto de que la cámara se reuniese al tiempo en que éste estuviese celebrando audiencia, indicándose que los demás «lo puedan hacer sin él» y que «no haya pena por no ir el alcalde» 23 .

De otro lado, por lo que se refiere a la gestión de la hacienda concejil, las Ordenanzas antiguas ofrecen noticias tanto acerca de los algunos de los principales ingresos del Concejo, como de los gastos a los que había que subvenir con los mismos. Así, junto a los ingresos procedentes de los propios del municipio -son mencionados expresamente los cerrados y las dehesas de la villa y de las aldeas [cap. 21]-, se hace referencia a diferentes servicios que se arriendan cada año y que permiten obtener ingresos al Concejo en concepto de explotación del peso, de la panadería, de las tabernas, carnicerías, etc.:

Otrosí, es mi merced y mando que las rentas del peso de las civeras y del pan cocido y tabernas y carniciería y tiendas, y otras rentas cualquiera que los dichos oficiales entendieren que cumplen a mi servicio y a provecho comunal del pueblo, que las pongan en renta o en fieldad, e las hagan coger [...] las cuales rentas ordeno y mando que anden de año nuevo en año nuevo y se pongan en almoneda un mes antes de Navidad y se rematen en las fiestas de Navidad [cap. 22].

Con el fin de garantizar la correcta gestión de esas rentas y su destino a los conceptos señalados, la propia Ordenanza determina que se designarán por el señor dos hombres buenos «diligentes y abonados, uno clérigo y otro lego», encargados de recibirlas y dar cuenta al Concejo «e a mí cada que se demandare» 24 .

\footnotetext{
23 Ordenanzas antiguas, caps. 15 y 16.

24 Para el año 1409 fueron designado el arcipreste de Nájera y Fernán Martínez de la Tabla, designados «dende en adelante en quanto mi voluntad fuere», ibídem, cap. 24.
} 
Junto a la recaudación y gestión de las rentas, el señor cedía, asimismo, al Concejo los ingresos que, en concepto de multas o caloñas, debían ser abonados por los que causasen daños en los bienes de propios del municipio, o en las heredades de los particulares, o que contravinieren lo dispuesto en las leyes y ordenanzas ${ }^{25}$. Finalmente, los ingresos del Concejo se completarían con una contribución anual derramada entre los vecinos. A tenor de las Ordenanzas de 1409, el repartimiento que alcalde y regidores podían realizar por este concepto se limitaba a cinco mil maravedís al año, disponiéndose que, en caso de precisar más, debería obtenerse licencia del señor:

Otrosí, es mi merced y mando que sea hecho repartimiento por los dichos alcaldes y regidores por las costas y gastos del concejo hasta en cinco mil mrs en cada un año, y no más. Y estas costas y gastos de concejo, que así hicieren, sean escritas pro su parte. Y si más fuere necesario de se repartir, que los dichos alcaldes y regidores, que ahora son, o los que fuere de aquí adelante, que lo hagan saber a mí, si fuere en la tierra. Si no, que lo hagan saber a mi mujer. Y de mi licencia, o de la dicha mi mujer, que hagan lo que les fuere mandado ${ }^{26}$.

El capítulo de gastos del concejo estaría integrado principalmente por los derivados de su propio funcionamiento -salarios de oficiales, papel y otros enseres, así como algunas exenciones a los vecinos más pobres- y por los más cuantiosos de reparación de murallas, calzadas, puentes, fuentes, etc. ${ }^{27}$, que, a juzgar por las reiteradas referencias en las Ordenanzas de 1409, debían presentar un estado lamentable, exigiendo un esfuerzo continuado al concejo para su mantenimiento:

Otrosí, por cuanto las cercas de esta villa están tan mal paradas y las calzadas y puente y otras labores del concejo desbaratadas y no se hace repartimiento alguno en ellas, pero el concejo por no haber rentas para ello, por ende es mi merced de dejar la penas y caloñas que a mi pertenecen en esta dicha villa e aldeas a vos el dicho concejo y mando que sean puestas en rentas, o so censos, en fieldad, en la manera que el alcalde y regidores que ahora son, o fueren de aquí adelante, hallaren que más cumple a mi servicio y a provecho de vosotros. Y lo que las dichas penas y caloñas rindieren, mando que se ponga en la dicha reparación y labores del concejo [cap. 20] ${ }^{28}$.

Esta a cesión por parte del señor de los ingresos procedentes de penas y caloñas se reitera en relación a las debidas a los daños causados en los tierras de cultivo [cap. 21] y a las que debían abonar los que trajesen vino de fuera tanto a la villa como a sus aldeas [cap. 19] y se extiende asimismo a las ya mencionadas rentas del arrendamiento de diferentes

\footnotetext{
25 Ibídem, caps. 19, 20 y 21.

26 Ordenanzas antiguas, cap. 28.

27 GoicoleA, Francisco Javier, »Navarrete a finales de la Edad Media...», cit., pp. 76-78.

28 Sobre la construcción y obras de reparación de la muralla, ÁLVAREZ CLAVIJO, M.T., »La muralla y el castillo de Navarrete (La Rioja) », Berceo, 146 (2004), pp. 137-171. En anexo 5 reproduce los capítulos 20 y 21 de las Ordenanzas antiguas, correspondientes a 1409, de las que dice fueron dadas en 1411, pp. 146 y 157.
} 
servicios, cedidas, igualmente, "para la dicha cerca y labores» 29 . Finalmente, las ordenanzas prevén también una prestación personal a cargo de los vecinos como contribución anual al mantenimiento de la muralla:

Otrosi, es mi merced y mando que, para ayuda de la dicha reparación de la cerca y labores, que cada vecino de la dicha villa y aldeas anden por verda en las dichas labores, un día o dos en el año, el que tuviere bestia, con sus bestias, y el que no tuviere bestia, con su cuerpo, so las penas que los oficiales les pusieren [cap. 23].

La villa de Navarrete y sus aldeas contribuían, además, anualmente en la cuantía que fuese señalada en concepto de «pedido» del señor y de servicio debido al rey ${ }^{30}$. La distribución de pechos se determinaba a partir de los padrones, efectuándose el correspondiente derramamiento entre los vecinos de acuerdo con lo estipulado en 1408:

[...] sabed que Yo, entendiendo que cumple a mi servicio y a provecho de todos vosotros, que acordé y mandé que, en razón de lo pedido y servicio de nuestro señor el Rey, que se haga repartimiento entre vosotros en esa manera: que la mayor cabeza sea hasta en cinco mil maravedís y, dende Ayuso, cada por lo que hubiere. E de esta manera vos mando que repartades y pagades el dicho servicio y pedido entre vosotros. $Y$ esta ordenanza y tasa mando que valga ahora y de aquí adelante en el pedido y servicio de nuestro señor el rey ${ }^{31}$.

A tenor de las Ordenanzas de 1409, el alcalde y los regidores deberían disponer lo necesario para evitar que algunos eludiesen sus cargas, resultando un mayor gravamen para los demás vecinos:

Otrosi por cuanto me fue dado a entender que en esta villa es de costumbre que cada uno pague el mi pedido y costas concejiles por lo que tenia, y cada vecino ha de contar sobre juramento todas sus heredades, y algunos [...] cuentan bien y andan más cargados en el pecho y llevan su cargo y el ajeno. Por ende, es mi merced y mando que si el alcalde y

\footnotetext{
29 «Otrosí, es mi merced y mando que las rentas del peso de las civeras y del peso y del pan cocido, y tabernas, y carnicería, y tiendas, y otras rentas cualquiera que los dichos oficiales entendieren que cumplen a mi servicio y a provecho comunal del pueblo, que las pongan en renta o en fieldad y las hagan coger y los maravedís que rindieren o valierren, sean para la dicha cerca y labores, las cuales rentas ordeno y mando que anden de año nuevo en año nuevo y se pongan en almeneda un mes antes de Navidad y se rematen en las fiestas de Navidad», Odenanas Antiguas, cap. 22.

30 A la luz de los Libros de cuentas, el pedido alcanzaba los quince mil maravedíes en 1542, constituyendo el segundo concepto de gastos, en orden de cuantía, sólo por detrás de los relativos a la reparación de la muralla y muy lejos de lo que importaban los gastos derivados del funcionamiento del propio Concejo, gastos militares, etc. Vid. GoicoleA, Francisco Javier, «Navarrete a finales de la Edad Media...», cit., p. 77.

${ }^{31}$ La Ordenanza está fechada en Redecilla, a 27 de mayo de 1408. En la sesión celebrada por el Concejo el 3 de noviembre de 1411, se leyó esta previsión, contenida en «una carta de nuestro señor Pero Manrique, adelantado, que Dios mantenga, escrita en papel, sellada con su sello de cera colorada en las espaldas y firmada de su nombre, según por ella parecía», acordándose que «por cuanto la dicha carta era escrita en papel y temían que se podría perder o rasgar», se solicitase autorización para sacar un traslado de la misma en pergamino, Ordenanzas antiguas, cap. 29.
} 
regidores, con sejo de buenos hombres, hallaren que cumple a mi servicio y provecho y bien del Concejo que el término y heredades sean y que lo hagan asi hacer, porque cada uno pague por lo que ha, sin encubierta alguna ${ }^{32}$.

La recaudación corría después a cargo de los jurados, ocupándose de recoger el servicio del rey «el jurado que fuese bolsero del Concejo», en tanto del pedido se ocupaba otro de los jurados, debiendo dar cuenta los dos al concejo y consignar en un libro lo recaudado en las aldeas ${ }^{33}$.

Finalmente, junto a las previsiones tocantes a la hacienda concejil, las ordenanzas antiguas daban cabida asimismo, entre otras cuestiones ${ }^{34}$, a algunas disposiciones relativas -como antes dije- a cuestiones de naturaleza procesal. Así, permiten conocer que todos los pleitos debían pasar ante el escribano del concejo ${ }^{35}$ y que el alcalde no admitiría escrito alguno de las partes que no fuese signado por el abogado o letrado que le asistiese $^{36}$. Las ordenanzas precisan que el coste de la asistencia de un letrado, en aquellos pleitos que el alcalde no pudiese librar por sí mismo debía ser abonado por ambas partes, imponiéndose posteriormente su abono íntegro por la parte que resultase condenada ${ }^{37}$. Y asimismo establecen los derechos que debían percibir los alcaldes en los procesos:

Otrosí, por cuanto he sabido que los alcaldes hasta aquí no llevaban derechos algunos de los juicios y sentencias que daban de sesenta maravedís Ayuso, ni condenaban en costas a la parte caída y por esto los hombres no habían temor ni verguencza de traer pleito y revuelta a aquellos a quien eran obligados a hacer o pagar alguna cosa. Y por esta razón había muchos pleitos maliciosos, en que perdían los hombres sus días y sus haciendas. Por ende, es mi merced y mando que, de aquí adelante, el alcalde lleve de la sentencia definitiva de sesenta maravedís arriba, cuatro maravedís y de la interlocutoria, dos maravedís, según se usó hasta aquí. Y de los juicios afinados de sesenta maravedís ayuso hasta diez maravedís, que el alcalde haya de derechos un maravedí. Y dende ayuso non haya derecho alguno. Y que estos derechos de sentencias paguen luego de mano aquel o aquellos a cuyo pedimento se dieren, pero que después lo pague la parte caída con las costas del pleito, en las cuales costas mando que sea condenada la parte caída, así en los pleitos de sesenta maravedís arriba, como en los de sesenta maravedís ayuso, según que es derecho. Y esto porque los unos vivan en paz y los malos y revoltosos, por temor de la pena, vivan en justicia ${ }^{38}$.

\footnotetext{
32 Ibídem, cap. 27.

33 Ibídem, cap. 26.

35 Ordenanzas antiguas, cap. 13.

36 Ibídem, cap. 8.

37 Ordenanzas antiguas, cap. 7.

38 Odenanzas de 1409, cap. 17.
}

34 Contemplaban también los salarios que debían abonarse a aquellos vecinos a los que se encomendase llevar recados al señor, especificándose la cuantía a percibir en atención a la urgencia y al empleo, por ende, o no de un animal que lo transportase, ibídem, cap. 25. 


\section{Las Ordenanzas para el buen gobierno de la villa de 1564}

Las Ordenanzas de 1564 llegan hasta nosotros en un traslado de comienzos del siglo XVII, dispuesto, a partir del original, por el teniente de gobernador y alcalde mayor de la villa y jurisdicción de Navarrete, Juan del Moral Castillo. El manuscrito presenta en algunas de sus páginas serias dificultades de lectura, debido a su deterioro. Junto a éste, se conserva también un traslado anterior, fechado en 1580 y mejor conservado, en el que constan únicamente la cabeza y pie del documento original y una de las ordenanzas aprobadas tres lustros atrás ${ }^{39}$.

El documento -que se publica en el siguiente apartado- contiene unas ordenanzas completas y extensas, que se dicen acordadas por la Justicia y Regimiento de la villa y, al tratarse de un lugar de señorío, confirmadas por el señor. Como es habitual en este tipo de documentos, constan de un encabezamiento en el que se da cuenta del lugar y la fecha en la que fueron aprobadas y se establece seguidamente quién sea el otorgante de ese texto normativo. Precede a la parte dispositiva una breve exposición que persigue informar acerca de la conveniencia y oportunidad de disponer las ordenanzas. A ésta sigue el texto de las ordenanzas, que se introducen una tras otra, numeradas de forma correlativa y precedidas de la fórmula «ordenamos», o de los vocablos «otrosí» e «ítem». Al texto normativo sigue la disposición de su inmediata publicación, registrándose, a continuación, el mandato de pregón, la indicación de haberse efectuado y la referencia a los testigos que estuvieron presentes en el acto de la publicación de las ordenanzas. Al tratarse de una villa de señorío, consta la petición de confirmación formulada por la Justicia y Concejo de Navarrete, a la que sigue la disposición confirmatoria por parte del duque. Como se puede ver en el texto transcrito, el traslado de 1607 incorpora también una diligencia de notificación a una de las aldeas de la jurisdicción de Navarrete ${ }^{40}$ y un traslado del poder conferido por los navarretenses a su procurador general para representarlos y defender sus intereses.

Las propias ordenanzas ofrecen noticias -como antes dije- acerca de su proceso de gestación. A tenor de las mismas, las autoridades locales de Navarrete habrían considerado la oportunidad de «tratar e comunicar las ordenanzas antiguas y las que más convenía ordenar de nuevo para la buena gobernación de esta villa». Fruto de diversas conferencias al respecto - «habiendo juntado muchas veces», recuerdan- y de la consulta con «otras muchas personas principales y honradas de esta villa», el concejo acordó, en sesión celebrada el 12 de febrero de 1564, que se guardasen en adelante las Ordenanzas que habían formado:

\footnotetext{
${ }^{39} \mathrm{La}$ ordenanza cuyo tenor se inserta en el traslado sacado por el escribano Juan Angulo, el 28 de enero de 1580, es la relativa a los «cortadores y pesos faltos» de las de 1564. Puede verse en AHPLR, Sección Judicial, caja 89/3.

40 Se trata de la notificación a la aldea de Daroca, de la jurisdicción de Navarrete, efectuada -a pedimento del procurador general de la villa, Miguel Roldan- el 28 de febrero de 1564. Se les notificaron las «ordenanzas atrás contenidas que tocan y hablan sobre los montes y pastos de esta villa y lugar de Sotes y Daroca, según en ellas se contiene y declara». Consta asimismo que por parte del procurador y del jurado de Daroca se dijo quedar enterados y se solicitó traslado de las mencionadas Ordenanzas, ibídem, «Ordenanzas hechas por la Justicia y Regimiento de esta villa de Navarrete para el gobierno de ella».
} 
Todos de un acuerdo y deliberación, después de lo haber muchas veces tratado y comunicado, dijeron que hacían e hicieron, y ordenaron las ordenanzas yuso declaradas. Las que mandaron que, de aquí adelante se guarden y ejecuten las penas, costas y daños conforme a ellas y según que por ellas van aplicadas.

Los impulsores de la reforma, dan cuenta, asimismo, de cuáles eran las razones que les habían determinado a decidir la revisión de sus ordenanzas antiguas y la composición de las extensas de 1564. Afirman así que las sanciones previstas en aquellas no resultaban adaptadas a la realidad del momento y que, además, en las mismas no se identificaba con claridad quién debía ocuparse de su ejecución. Por esta razón, entendían que habían resultado «mal guardadas» y que existía gran desorden «y nadie era señor de su hacienda, fruta y árboles, y sarmientos, ni otra leña de sus heredades...».

Resueltos a corregir los problemas detectados, «todos de un acuerdo y deliberación» dispusieron las que, el traslado de 1607, cataloga como «Ordenanzas hechas por la Justicia y Regimiento de esta villa de Navarrete para el gobierno de ella». Un texto normativo extenso, que se ordenó publicar inmediatamente «para que venga a noticia de todos y nadie pueda pretender ignorancia» y de cuyo cumplimiento y ejecución de las penas previstas en las mismas se hizo principal responsable al procurador mayor, encargado de custodiar el original del que se le hacía entrega, disponiéndose además que se conservase un traslado signado de las mismas en el arca donde debía depositarse la documentación del concejo:

el procurador mayor que es o fuere las tenga en su poder y tenga cargo de las hacer guardar y ejecutar, hacer cobrar las penas que se aplicaren para el concejo.

La publicación debía llevarse a cabo inmediatamente, mediante pregón en la plaza pública de la villa «con voz de pregonero, para que venga a noticia de todos», según acordó el concejo el mencionado 12 de febrero de 1564. En su cumplimiento, en el día siguiente, el escribano del concejo daba fe, mediante diligencia inserta al pie de las ordenanzas, del cumplimiento de la orden de publicación:

... los dichos señores Justicia y Regimiento hicieron apregonar y se apregonaron estos capítulos y ordenanzas arriba contenidos, por voz de Juan de Huessa, pregonero público, el cual dicho pregonero las apregonó en altas e inteligibles voces, leyéndoselas yo, Diego Ballestero, escribano público de la Real Majestad y del Ayuntamiento de esta dicha villa.

Acordadas y hechas pregonar, el procurador general del concejo de Navarrete solicitó del duque de Nájera la confirmación de las Ordenanzas aduciendo que «eran buenas, justas, útiles y provechosas a la dicha villa». La confirmación de la autoridad señorial tuvo lugar el 24 de abril de 1564, ordenándose que se guardasen y ejecutasen en adelante en la villa y en sus términos y jurisdicción.

Por lo que se refiere a su contenido, no difiere del habitual en este tipo de textos normativos a través de los que los concejos, en el ejercicio de la potestad de ordenanza 
que corresponde al municipio, se dotan de numerosas normas atentas a la regulación de los más variados aspectos de la vida en el lugar.

En el caso de las Ordenanzas de Navarrete de 1564, en efecto, los primeros capítulos de se refieren a extremos relacionados con el funcionamiento del concejo. Por ellos desfila así el conjunto de las autoridades locales: el gobernador de la villa y su jurisdicción, los regidores, el procurador mayor, los diputados. Junto a ellos, el escribano del concejo, el mayordomo o los contadores. Se trata, en todo caso, de un reducido número de capítulos, en los que se regulan, por una parte, los días en que debe reunirse el concejo, la obligación de asistencia a los ayuntamientos y la de guardar secreto acerca de lo tratado en los mismos. Por otro lado, se presta atención detenida a la conservación y custodia de la documentación generada por el concejo. Y finalmente, se incorporan algunas normas sobre la elección de oficios concejiles y sobre las obligaciones y derechos del concejo en relación al Hospital de peregrinos existente en la villa.

El grueso de las ordenanzas se refiere a la ordenación del campo, dando cabida, por un lado, a disposiciones de carácter general sobre huertas, cerrados, huertos comunes, corrales, viñas y asimismo sobre los bienes de propios del municipio, como la denominada Dehesa de la Verde. De otra parte, un buen número de capítulos se refiere a las prácticas lesivas para el campo, precisando, en cada caso, las sanciones que corresponde imponer a los infractores de las Ordenanzas. Finalmente, otros de los capítulos permiten conocer las funciones asignadas a los guardadores del campo -los denominados custieros-, cómo deben desempeñarlas y asimismo la intervención del procurador mayor, en tanto que responsable último en el concejo de la salvaguarda de las viñas, huertas y heredades, que, las propias Ordenanzas, describen como la principal granjería de la villa.

Con todo, un buen número de capítulos tiene por finalidad ordenar el abastecimiento de la villa y su entorno y el desarrollo de actividades comerciales en la misma. Al concejo corresponde procurar que los vecinos estén en todo tiempo suficientemente abastecidos de los productos que se consideran indispensables: carne, pan, etc. Las Ordenanzas de 1564 dedican así, prácticamente una tercera parte de sus capítulos, a ordenar las carnicerías, el peso de la harina, o el despacho del pan. Junto a estos, las tiendas y la regatonería merecen asimismo una regulación precisa, prestando especial atención a la comercialización del vino, su venta en las tabernas, la reventa y la prohibición de meter vino de fuera de la villa.

Finalmente, en menor medida, estas ordenanzas extensas de Navarrete contemplan también cuestiones que podemos considerar de policía. Esto es, disponen diferentes normas que persiguen una convivencia ordenada en la villa, tipificando, así, actividades de muy diversa índole que, por considerarse lesivas para los intereses comunes o particulares de algunos vecinos, son prohibidas por las Ordenanzas, estableciéndose la correspondiente multa para los infractores. 


\section{APÉNDICE DOCUMENTAL}

[pag.1]

«Hordenanzas particulares dela villa de Nauarrete. Año de 1564»

\section{[pág.2 y ss] \\ «Hordenanzas hechas por la Justiçia y rrejimiento de esta Villa de Nauarrete para el gouierno deella. Confirmadas por el Duque de Naxera Mi Señor. Año de 1564»}

Las quales se an de Guardar cumplir y ejecutar como enellas se contiene, las quales hiço sacar el orixinal el Señor Juan del Moral Castillo siendo tet.e de gouernador y Alcalde Maior en esta villa y su jurisdiz ${ }^{0}$. Año de 1607 y lo firmo =Juan del Moral Castillo=

En la Villa de Nauarrete a doce dias del mes de feb ${ }^{\circ}$ de mill quinientos y sessenta y quatro años los mui magnificos señores Justicia y rregimiento e ayuntamt ${ }^{\circ}$ de la dha villa estando juntos en su auintamiento como lo tienen de costumbre de se ayuntar siendo llamados para este efecto especialmente los mui magnificos señores = Sebastian de Bergara gouernador de la dha villa y su tierra y jurisdiz ${ }^{\circ}$, Juan Varragan Regidor $=$ Miguel Roldan, pror. xeneral $=$ Martin fernandez Navarrete, fco gonzalez $=$ Juan de Navajas Juan de Ayala Pedro Perez Calahorra diputados de dho aiuntamto que estando asi juntos rrepressentan dho aiuntamto o la maior partte de el por ellos y en nombre de los ausentes por quienes prestaron capzion auiendose juntado muchas beces é auiendo llamado otras muchas personas principales y honrradas desta dha villa para [tratar e comunicar] las hordenanças anteriores las quales conbenia ordenar de nuevo para la buena Gobernaz ${ }^{\circ}$ de esta villa, los montes de pastos y viñas e pieças guertas y cerrados arvoles fuenttes aguas é otras cossas atento que esta villa no tiene otro trato ni granjeria que las viñas y heredades = Visto las hordenanças antiguas por no haver penas congruenttes ni perssona diputada que ejecutasse aquellas ansi de mal guardadas y a hauido gran desorden y que nadie era Señor de su hazienda frutos aruoles sarmientos ni otra leña de sus heredades. Todos de un acuerdo é deliveraz ${ }^{\circ}$ despues de lo aver muchas beces tratado é comunicado dijeron que hacian é hicieron e ordenaron las ordenanças yusso declaradas. Las q mandaron quede aqui adelante se guarden y ejecuten las penas costas y daños conforme a ellas é segun [que por ellas] ban aplicadas y para que benga a noticia de todos y nadie pueda pretender ygnorancia se pregonen publicamente y el pror. maior que es o fuere las tenga en su poder y tenga cargo de las hacer guardar y executar acer cobrar las penas que se aplicaren para el concejo y que otro traslado signado se ponga en el arca del aiuntamiento y las ordenanças son del thenor siguiente.= 
1

Horden para los aiuntamientos.

2

Lo mismo.

3

Sobre el

descender los

oficios

4

Sobre las

escripturas del

concejo.

5

Sobre el bissitar los ospitales.
Primeramente ordenamos que para que mejor sean gouernadas y rregijas las cossas combenienttes a la Republica comformandonos conl a costumbre antigua = que se juntten en el aiuntamiento dos dias en la semana que an de ser Marttes y Sauado de Mañana. Desde primero de Março fasta primero de Sepre a las Siette oras = y la otra mitad del año a las ocho de la mañana. La justicia y rrejidores pror maior é diputados y el Scrivano de Camara los qs todos allandosse en la villa bengan a los dhos aiuntamt ${ }^{\circ}$ so pena de cien [mrs.] por cada bez que faltaren cada uno aplicados para el dho aiuntamiento los quales le sean luego ejecutados = y si alguno ô algunos faltaren en benir que los que binieren agan el aiuntamt ${ }^{\circ}$ con la justicia y ejecuten la pena [sin] los que faltaren y que el maiordomo de la villa asista a los aiuntamientos para que mande a los contadores que guarden y esten a la puerta para que haga lo que les fuere encargado por los del Aiuntamiento.

Otrosi que en el dho aiuntamiento las cossas que se acordaren se asienten por ante el Scrivano de el aiuntamiento y lo firmen todos los que se allasen en el y las cossas que en ellos se acordren de que dieren cargo alguno de el aiuntamiento bengan dando rraçon de ellos para el primer aiuntamiento y en las cossas que en el se trataren se guarde el secreto de ellas so pena de una Comida por cada bez para el dho aiuntamiento gastada y en la manera que el aiuntamiento hordenare.

Otrosi que los becinos que ubieren entrado en el aiuntamiento y tenido ôficios en ella no puedan ni esten obligados a descender en oficios de menor calidad que los que ubieren tenido y esto se entienda de todos los oficios que se elijen en esta villa comforme a la costumbre antigua.

Otrosi que los Rejidores y el pror. maior sean obligados a tomar quenta con ymbentario los nuebos a los biejos dentro de quince dias por antte el Scrivano de Camara de todos los papeles scripturas y previlexios de esta villa so pena de seiscientos mrs para las obras publicas desta villa y que quando alguna scriptura tocante al concejo se ubiere de sacar de la arca donde estan se saque de el. antte los rrejidores é pror. maior y el scrivano de Camara é aia libro en que asientten las scriptturas que se sacaren y se tome conocimiento del que las llevare y se assientte como las boluiere so pena de cinco mill mrs pro cada bez aplicados para obras publicas desta villa.

Otrosi porque combiene mucho al seruicio de Dios nro Señor que los ospitales desta villa sean Mirados, e bisitados para ber como tratan los peregrinos que llegan a ellos que la justicia y rregidores é diputados baian todos los Savados en saliendo del aiuntamiento aberlo sussodho y prober en ellos lo que bieren es necessario a lo menos baian cada sauado un rregidor y un Diputado. 
6

Sobre los bienes $y$

Rentas del ospital

7

Carnicerias

8

Cortadores y pessos falsos.

9

Los vientres $y$ assaduras los sauados

10

Que no maten carneros por capar en cierto tiempo

11

las tripas
Otrosi que los Regidores y pror Maior tenga quenta de hacer ymbentario de los bienes de los ospitales y érmitas y cada un año se de un traslado a los Maiordomos de los ospitales y hermitas para que por el cobren las Rtas de ellos y los tales Mayordomos den quenta dellas é aia un ymbentario de dos bienes e $\mathrm{Rt}^{\mathrm{a}}$ signado y autorizado en el arca de las script ${ }^{\mathrm{a}} \mathrm{s}$ del concexo.

Yten que en esta villa a ia dos Vancos de Carne auierto todo el año é dos Cortadores en ellos a contento de la Justicia é aiuntamiento en los quales se de buena Carne e no émferma ni dañada so pena que la tal Carne sea échada a la Caua é de seiszientos mrs de pena al probedor = é otros seiscientos al Cortador que la bendiere por cada bez aplicados por terceras parttes para la Justicia é denunciador. = otro si que se embie al rreuaño a traer Carneros y Vacas a costa del probedor.

Otro si que los Cortadores sean mui leales en sus oficios pessando bien la Carne é si les allaren pessos falssos los fieles ô otras perssonas que paguen por una blanca beinte mrs e por un marauedí quarenta é por dos mrs Duzientos aplicados por terceras parttes para el concejo Justicia é denunciador e por los pessos falssos de dos mrs arriva se este a la pena que la Justicia e aiuntamiento les quisieren cargar y el fiel de el pesso en principio del año tenga libro con que asientte los pessos falssos é que si en un dia se le allaren diez pessos de Mediablanca falta tenga de pena beintte mrs de todos diez pessos.

Otrosi que los Carniceros sean obligados d ematar cada sauado seis carneros para la justicia é aiuntamiento é otras perssonas principales para que les den pr sus dineros sus dineros los bientres é assaduras so pena de seiszientos mrs aplicados para el concejo, Justicia é denunziador por tercias partes.

Otrosi que de el dia de S. Pedro de Junio adelantte en cada un año no se maten en dhas Carnecerias Carneros por Capar so pena por cada bez que los mattaren pagar el provedor ô Cortador seiscientos mrs y el tal Carnero se de a los pobres= Otro si que los Cortadores tengan la Carne publica y no escondida en cassa ni en botiga ni en cestas so pena de cien mrs por cada bez $=\mathrm{Y}$ otro si que en ningun tiempo del año quiten las rriñonadas a los Carneros si no que las pessen con la Carne so pena de cien mrs pro cada bez que las allaren quitadas aplicadas las dhas penas para el concejo justicia é denunciador por tercias partes.

Yten que las tripas de las vacas se bendan lauadas cerradas los días de carne el precio que se tomare la postura con el aiuntamiento so pena de cien mrs aplicados para el concejo y denunciador por mitad y que los Sauados no sea la tripera obligada a dar las rraidas sino lauadas $=$. 
12

Tiendas

13

Lo mismo.

14

Lo mismo y pesos

falssos

15

Tenderos

16

Fieles de la

balanca.

17

Dros de los fieles de valanças.
Yten que en esta villa aia dos vancos continuamente de tiendas puestos en lugares combents en los quales se den las provisiiones avasto asi en los dias de quaresma como en todo el año y que los Tenderos o los que por ellos dieren las tales provisiones sean perssonas de buena fama y contratazion a contento de la Justicia é aiuntamiento y tengan las provissiones de Congrio y pescados en partes limpias que no esten humedas so pena de Duzientos mrs por la primera bez aplicados para el concejo Justicia é denunciador por terceras parttes y de las otras beces que hicieren lo contrario paguen la pena que la Justticia é rregimiento mandaren é que los rregidores o fieles é pror maior tengan cuidado de lo visitar y que el un banco este de la placa abajo y el otro de la placa arriva.

Yten que los dhos Tenderos tengan buenas Valanças y pessos [maezidas] y señaladas por los fieles de la dha villa en el principio que tomare las tiendas y que las balanças en que se pessare el pescado sean aujereadas por auajo que no se detenga el agua en ellas e que el pescado remojado tengan en una gamella limpia y sin agua é sobre tabla para que de alli se pessen so pena de Duzientos mrs pr cada bez para obras publicas.

Yten que si a los dhos tenderos o a sus ofizs les fueren tomados algunos pessos faltos y éscassos que paguen la pena de cada blanca beintte mrs é de cada marauedi quarenta é de dos mrs Duzientos aplicados pr tercias parttes para el concejo justicia y denunziador é de los tres arriua paguen la pena que la Justicia é aiuntamiento mandaren.

Otro si que los dhos tenderos no puedan Comprar quesso ni Sardinas frescas ni Castañas ni garuanços ni otras cossas que se binieren a bender a esta villa el dia que llegaren fasta que los becinos se aian proveido so pena de Duzientos mrs por la primera b ez é por la segunda Setezientos aplicados pr tercias parttes para el concejo Just $\mathrm{t}^{\mathrm{a}} \mathrm{y}$ denunciador y que el dia que lo compraren queriéndolo los $\mathrm{tt}^{\mathrm{0}} \mathrm{s}$ de darsselo pr lo que les costare $=$.

Yten que los fieles desta uilla tengan mucha dilijencia en rrequerir las Carnicerias y tiendas y vancos de las otras perssonas que benden Mercadurias y ber como son seruidas bisitando las pessas y medidas y tengan balanças y marco de las pessas de concejo y la cantara é media azumbre y las otras pessas e medidas para que con ellas [maiezan] las pessas e medidas de los otros ofiziales y tengan libro en el qual asienten todos los pessos y medidas faltas para que se sepa como biue cada uno y que los dhos fieles cada sauado bengan á da5 racon y quenta de lo que les madaren los Sres Justicia y rreimiento.=

Yten que todos los filees tengan dro de [maezir] los pessos e medidas de esta uilla y su jurisdizion de la media fanega ocho mrs y del celemin con medio celemin ocho mrs, de las medidas para medir la sal por menudo dos mrs de una 
Cantara ocho mrs de la media Azumbre quatro mrs de las medidas pequeñas a dos mrs por cada una. Y de la smedidas de azeitte quatro mrs de cada una y no lleuen mas so pena de Cien mrs por cada bez, aplicados para el concejo Justicia y denunziador por terceras partes $=$.

18

Dros de los files del Campo.

19

Pesso de la arina.

20

Molineros

21

Lo mismo

22

Pesador de la arina
Yten que los fieles del Campo aian de dros de apreciar cada aruol quattro mrs y esto se entienda con aruoles que no sean diferenttes y en cada heredad y en sacar el aprecio quatro mrs y delas [coseras] quatro mrs y en lo demas comforme al tiempo que se ocuparen entiendasse que por muchos aruoles de un jenero y en una heredad pueda lleuar los uqatro mrs y no mas=.

Yten que el pesso de la arina y [hauerio] de esta uilla este bien adreçado para que se pessen las Cargas de trigo anttes que bayan al molino e quando los traigan, en el qual este una buena perssona de comfianca y tenga libro en que escriua lo que pessaren e de al dueño Memoria deello para ber si biene bien quando las buelben y lleue el pessador un Marauedi de cada carga e pesso que hiciere fasta una fanega e que el molinero que lleuare Cebera sin pessar a los molinos que paguen por cada fanega cada bez trezientos mrs aplicados para el concejo Justicia y dueño e denunciador por quartas partes=.

Yten que los molineros sean obligados de benir a esta uilla por Cargas con las açemilas e con personas del recado para que lleuen e traigan las cargas a sus dueños y que el Molinero que no biniere por las cargas pague de pena Cien mrs por cada bez e el pessador le pueda tomar la bestia e que auiendo [Çeuera de la baia] no baya por [Ciuera] ni la muela de otra partte so la dha pena aplicada para obras publicas desta uilla.

Yten que dhos Molineros hagan buena arina bien molida e tal como deuen e si tal no ficiere que el dueño la muestre a los rrexidores los q la agan ber a dueñas experimentadas para ber si es buena e si tal no fuere que la hagan dar al Molinero el qual pague otras tantas fanegas de trigo al dueño en arina buena que tenga otro tanto pesso como el trigo tenia.

Yten que el pessador dela arina sea obligado a tener una arca en dho peso y que lo menos tenga de arina su media fanega de arina para que supla las faltas que ubiere en el pesso del trigo que hubiere pessado e lo é de supla de la dha arca luego e cobre el pessador del molinero que lo Trajere falto y lo pueda detener y tomar el ganado que trajere con la arina o otra prenda fasta que la cobre so pena que el pessador que no lo cumpliere e no hiciere tener la dha arca con arina pague de pena Cien mrs = Y otrosi que el pessador no consienta descargar en el pesso Cargas de arina sino que luego las lleuen so pena de otros Cien mrs aplicados para la Justicia e concejo e denunciador por terceras parttes y que los rrejidores y pror Maior tengan cargo de uisitarlo para ber como se hace. 
23

Corredor del vino.

24

Que no metan bino.

25

Vino comprado.

26

Venta de vinos por Tauerna esta uilla.
Yten que el Corredor de el bino lleue de Cada Carga de bino que se sacare desta uilla un Marauedi y del sacar de los Cueros de las Cuebas de cada Cuero un Marauedi y de liar otro y de [leher] las Cantaras si los echare la perssona que el pusiere una blanca de Cada Cuero e de sacar cada Cuero de quatro Cantaras arriua tres blancas no mas y que no pueda lleuar el corredor dadiuas algunas por hacer bender el bino de ello directa ni yndirecta en dineros ni otra cossa por si ni por otra perssona ni por ninguna encubierto ni color aunque Graciosamente se lo quieran dar que saue y tiene entendido que si el hiciere graciosamente su oficio a como es obligado que no se lo darían.

Yten que no pueda por si ni por otra persona lleuar Jarros de vino grande ni pequeño de los que benen el bino aunque se lo den graciosamente por el gran daño que la Experiencia a mostrado que la republica desta uilla a rreciuido porque se a bisto tener Tauerna publica los Corredores de los Jarros que rreciuen de los bezinos desta uilla todo el tiempo que dura la benta del bino lo qual es en menos precio de los que Gouiernan so pena de qu pague lo que ansi reciuiere con el quatro Tanto aplicados por terceras partes para el concejo e justicia e denunciador $=$ Otrosi que el dho Corredor no pueda lleuar [los So] a nenguna perssona ni mulatero en mucha ni en poca cantidad so pena de mill mrs por cada bez que lo lleuare apolicados segun de suso.

Yten que ni Ningun Vezino desta uilla ni fuera de ella ni los Sindicos delos frailes de San Francisco no puedan metter bino en esta uilla de fuera partte so pena de mill mrs por cada bez que lo metieren y el bino y los cueros perdido aplicados todo por terceras parttes para el concejo Justticia e denunziador y este se entiende de qual quier bino y mtiendolo sin lizencia de la Justitcia e un Rejidor y procurador maior.

Yten que todos los bezinos desta uilla e fuera de ella que compraren en ella bino para tornar a bender sean obligados de ellos a dar para Taberna o [rrecuus] de el dia de Todos Santos en adelante pidiendose lo la Justicia e rrejimiento cada e quando que se lo pidieren e mandaren bender sin que se les tome en quenta para las Tassas y que lo den aunque no aia tassa y que primero lo hagan dar a los becinos de fuera parte que tubieren comprado bino en esta uilla o otros por ellos dando todo lo que tubieren comprado que no a los becinos desta uilla lo que sea y se entiende que se pueda tantear y tomar dentro de Treinta dias desde el dia que lo uibieren comprado y que lo bendan a la postura del Concejo que ubiere al timepo que se lo tomaren.

Yten que a los becinos desta uilla que ehasen a bender bino blanco e tinto sean olbigados de lo hacer pregonar publicamente al precio que lo tubiere puesto por la Justicia e rejimiento de la dha uilla epidan a los fieles medidas para los medir e no los midan ni Vendan a mas precio de lo que estubiere puesto ni 
sin les dr medidas los fieles so pena de seiscientos mrs que esto se entienda en lo de el pregonar asi mismo echando otra cuba y la dha pena apolicada para el concejo Justicia e denunciador.

27

Lo mismo y la orden de bender el biejo

28

Regatones

29

Que las

mercaderías

vengan a la

plaça.

30

Que no se compre pan en grano asta despues de medio dia por los panaderos mesoneros o obligados

31

Que no se compren cabritos ni corderos $p^{a}$ vender

32

Los jurados
Yten que qualquier Vecino desta uilla sea obligado mientras bendiere bino a Tauerna de dar dos Cantaras al becino que se los pidiere al precio que estubiere puesto el bino y si diere cantareado a la rrequa so pena que lo den debade y que todas las perssonas de qualquier estado que sea que bendieren bino en esta uilla sean obligados a lo dar segun se ordenare en aiuntamiento y el que no quisiere dar se lo pueda hacer dar y bender a su costa executar le la pena que le pusieren que quando alguna Cuba se echare por prenda no se eche otra fasta que aquella se acaue.

Yten que los rregatones no bendan Cossa alguna sin postura de los rrexidores desta uilla ni a mas precio de la postura so pena de Duzientos mrs aplicados para el concejo Justiica y denunciador.

Yten que ningun becino desta uilla pueda bender ni consentir bender en su cassa ninguna mercaderia que benga de fuera â esta uilla fasta que benga a la plaça y esto leña huebos berduras y frutas y pan cocido so pena de quatrozientos mrs por cada bez y que el mesonero no lo pueda comprar so la dha de los quatrozientos mrs aplicados por terceras parttes para el concejo justicia y denunciador.

Yten que las panaderas ni el obligado a la panaderia ni los mesoneros no puedan comprar pan en grano en la placa desta ciudad fasta la una despues de medio dia so pena de Ducientos mrs pr Cada bez aplicados por terceras parttes para el concejo Justicia y denunciador e que ninguna persona lo pueda comprar para ellos so la dha pena y esto se entienda sin licencia dela justicia e rreximiento.

Yten que ninguna persona pueda comprar Cabritos ni corderos en esta dha uilla ni en su jurisdicion para rreuender so pena de duzientos mrs por cada bez que los compraren y bendieren aplicados por terceras partes para el concejo justicia y denunciador.

Yten que los jurados de esta uilla prenden por los libros de sus cojidas a las personas en ellas contenidas en todo el año de su Juraduria e no puedan traerlos arrendadores ni otras personas sino fuere para les aiudar a traer las prendas a cuestas para que el andador no entre aprendar e que no puedan tomar para las 
cojidas los bustos de el concejo saluo que anden por las cercas y calles a cobrar los mrs de sus libros de los bienes mejor parados que se allaren e que despues de passado el año de su oficio si algun becino les deuiere algo de las tales cojidas baian a la justicia para que les den un andador para que prende e desele al andador un marauedi por cada prenda que sacare y carguesele ala prenda y si los dhos jurados se les dire a ejecutar por los mrs de sus cojidas que no paguen costas pues tienen costas trauados en su año ni en el otro siguientte fasta san Juan y lo mismo se haga con los otros ofiziales de el concejo entiendasse que todo el tiempo de el año se le mande dar el Jurado al andador para sacar prendas y que cobre por su terceros.

33

Que no traigan

obejas ni cabras

en partes

bedadas e qe hagan corrales $p^{a}$ les rrecojer.

34

Sobre el apaçentar antes de missa.

35

Guertas y

Cerrados.
Yten que por quanto la ordenanca puesta y asentada por la Junta de todas las uillas por la gran estrechez de terminos que ai en dhas uillas que ningun bezino de ellas traiga obejas ni cabras entre pagos ni en las huertas ni en otras parttes bedadas por los concejos de las dhas uillas so las penas que estan sobre lo susodho asentadas e que ansi mismo el becino de dhas uillas e de qual quier de ellas que tubiere obexas tenga su corral para las rrecoxer fuera partte donde siendo pedido por es tal becino que tubiere las dhas ouexas en la junta para que se le diputten lugar combenientte donde tenga buenas entradas y salidas sin perjuicio de las eredades de los becinos de las dhas billas se le den e que bistasn que la dha ordenança es mui antigua y necessaria al bien e procomun desta dha uilla se guarde e cumpla dende aqui adelante.

Yten que qual quiera que apacentare ganados en dias de pasqua e de nra Señora e de agosto e Domingo e fiestas solennes anttes de missa maior tenga de pena cinquenta mrs aplicados por mitad para la fabrica e para el arrendador e denunciador.

Yten que qualquier Vezino e morador desta uilla o fuera de ella que fuere tomado o por pesquisa allado dentro de nuebe dias que entro en qualquier Cerrado o huerta cerrada delos terminos desta uilla e sobre las tapias della para hacer daño que por el mismo echo cada vez pague seiscientos mrs de dia y mill y ducientos de noche demas y aliende de el daño que hiciere apreciado para el dueño y esto aunque ponga color que entro contra uista a caçar $\hat{u}$ a buscar birotte ô a la caça muerta aplicada la dha pena para la Justicia e Concejo e dueño e denunciador por quartas parttes y si el dueño denunciare lleue las dos partes y el que entrare en seguimiento del agua por donde tiene costumbre de rregar y entrada y salida para ello en la pena sino fuere entrado a açer daño ô apartandosse del camino por do tiene costumbre de yr a echar el agua en seguimiento de ella $Y$ entiendasse que la huerta cerrada la eredad que estubiere cerrada y cerrada con puerta y llaue y a lo que tubiere esto y estubiere entre heredades cerradas aunque en medios de entre unas y otras esten caidas las tapias o auierto que sean hauidas por heredades cerradas e aian lugar las penas 
de arriua e ansimismo sean hauidas por heredades cerradas aquellas que tub ieren lo susodho aunque hacia los caminos y eredades auiertas se les aian caido algunas tapias pareciendo que no an estando caidas de tres messes arriua y se ejecutte en ellas la pena como en heredades cerradas e lo sussodho se entienda en perssonas poruqe si algun ganado entrare por las tapias derribadas sin ser guiado que en este Casso pague el dueño del ganado dos Rs para el concejo ô dueño a la partte y si por casso el ganado fuese metido en las tales eredades e saliendose por las Tapias caidas o rrompiendolas que tenga la pena de los seiscientos mrs de dia e mill y ducientos de noche aplicada por quartas parttes para el concejo justicia e dueño e denunciador e sean hauidas por heredades cerradas para que en ellas aia lugar la pena de los seiscientos mrs y mill y ducientos de noche aquellas que por una partte olas cercare el rrio e matas y estubieren por aquella partte con tal valladar que no puedan enttrar ganados $y$ por lo demas estubieren tapiadas con puertas y llaue.

36

Sobre el andar entre guertos $y$ cerrados.

37

Los guertos.

38

Cojer fruta de lo axeno.
Yten que ninguan Perssona pueda andar entre huertas y cerrados las fiestas e Domingos mientras missa ni de noche ni ningun dia de noche sin caussa lexitima so pena de Ducientos mrs de dia e doblados de noche aplicados por tercias parttes para el concejo o para la Justicia e deunciador.

Yten que qualquiera perssona que fuere Tomado o por pesquissa allado hauer echo daño en la fruta ô aruoles ô ortaliça de los huertos comunes que demas del daño tenga de pena Cien mrs e doblados de noche aplicados para la Justicia Dueño e Concejo e denunciador por quartas parttes y que el ortelano que estubiere en la Cassa de los huertos jure en cada un año de manifestar cada sauado las prendas que hiciere en los meses de junio e jullio agosto e septiembre y en los otros messes en fin de cada mes y que no pueda criar gallinas en la dha Cassa so pena de Cien mrs aplicadas segun de susso.

Yten que qualquiera Perssona que fuere Tomado cojiendo fruta de lo ajeno pague de pena por cada bez dos rr de dia e quatro de noche aplicados para el concejo Dueño e denunciador e si fuere Tomado con Cesta o aldada o mangada o talega pague de pena quatro Rs de dia y doblado de noche aplicados segun de susso y esto se entienda demas de el Daño para la partte y sea hauida para [lelada] o capillada mangada o talegada de quatro [levas] arriua e de Doce manánas e peras Duraznos o Semejanttes frutas e de seis menbrillos arriua e de Cereças guindas o Ciruelas o almendras en beces fasta Cinquenta e doce nauos o treinta [seguras] de abas arriba e al Caminantte diez mrs esto para los guardas y lo mismo se entienda en otras legumbres entiendasse que si no es tomado de noche con Talegada ô mangado ô Capillada o mas que la pena se aplica por quartas partes para el concejo justicia Dueño y denunciador=. 
39

Ortaliças.

40

Hubas de viñas axenas.

41

Que no se rracime sin $\mathrm{liz}^{a}$ dela Justicia.

42

Aruoles de fruto

43

Ramas de aruoles.
Yten que qualquiera que fuere tomado por pesquissa de Nuebe dias allado que â entrado e lleuado berças ô ceuollas ô otras ortaliças tenga de pena Ducinetos mrs pro Cada bez aplicdos para el concejo justiica dueño e denunciador y mas pague el daño que es de cada [gramo] de berças quatro mrs e de cada ceuolla dos mrs e de cada puerro una blanca e de cada caueça de ajos un marauedi e de cada melon e calauaca un rreal e de cada pepino ocho mrs e si fuere de noche la pena doblada e si ganados comieren paguen de pena por cada bez un rreal para el concejo e deunciador por mitad e mas pague el daño como fuere apreciado por los fieles.

Yten que qualquiera perssona que trajere de biña ajena cesta de ubas pague de pena trezientos mrs de banasta doblado aplicado para la justicia concejo e denunciador y de noche la pena doblada y mas pague el salario a la partte.

Yque qualquiera que rracimare en viña ajena por pesquissa de nuebe dias o se supiere no auiendo dado lizencia la justicia errejimiento para aracimar pague de pena por cada carga seiscientos marauedis apolicados por quartas parttes para la justicia Concejo dueño e denunciador e de cada banasta ducientos mrs e de cada cesta cinquenta mrs aplicados por terceras partes para el concejo dueño e denunciador y mas pague el daño que sea media cantara de bino de cada obrada y al ganado que la comiere pague de pena de cada obrada media cantara de bino no estando apreciada que estandolo pague el aprecio.

Yten que qualquiera perssona que fuere tomada o se supiere por pesquissa dentro de medio año cortando ô auiendo cortado o arrancando aruol que tenga pena en los terminos desta uilla que demas de el dño que fuere apreciado pague de pan si fueren perales o cermenos o mançanos mill mrs de cada uno y de los ottros aruoles de fruta quinientos mrs de cada uno aplicaod para la Justicia Concejo e dueño de denunciador e si ganados los quebraren o parecieren siendo del primero año puestos el aruol pague de pena un rreal y de el siguiendo dos rreales y del tercero año tres rr para el dueño concejo e denunciador demas del daño por terceras partes y el daño para el dueño y el daño se tase en otro tanto como la pena y de alli adelante auido por aruol.

Yten que qualquiera que cortare o parciere por pesquissa hauer cortado rramas de los dhos aruoles Perales cermenos y Mançanos e otros qualesquier aruoles de fruto paguen de pena por cada rrama dos rreales de dia e doblado de noche aplicados por terceras partes para el concejo dueño e denunciador y mas el daño al dueño y de cada rramo pequeño con fruto que pareciere hauer cortado pague diez mrs para el dueño del aruol de mas de la pena sussodha aplicados segun de suso Entiendasse que siendo las ramas de los principales y estando con fruto la Justicia tenga quarta partte de la pena. 
44

Aruoles sin

frutos.

45

Oliuos.

46

Cepas.

47

Yemas.

48

Sarmientos.

49

Çepas y Sarmt ${ }^{\circ} \mathrm{S}$

antes de hacer la

sarmentera.
Yten que qualquiera que cortare o arrancare o por pesquissa de seis meses se allare auer cortado o arrancado aruoles sin fruto como son olmos alamos salces tiemblos ô plantones de oliuo ô otro qualquiera aruol sin fruto pague por cada uno trecientos mrs aplicados para el concejo justicia dueño e deunciador por quartas parttes y mas el daño a la parte y por los plantones o rramas que cortare de otro aruol pague la mitad de la dha pena aplicada al concejo deuño e deunciador y el daño a la parte y den quenta de los dhos aruoles los custieros.

Yten que demas de los susodho por ser los oliuos tan prouechossos y peligrosos y poque se apliquen a los plantar e criar que de aqui adelantte que qualquier ganado que comiere o rroiere qualquier oliuo o rramas de el que fuere de fasta quatro años e dende auajo que pague de pena tres rr pro cada bez aplicados para el concejo Dueño e denunciador y mas pague el daño a la partte el qual dende agora para euitar pleitos queda tassado en dos rrs de cada oliuo damnificado demas de la pena y que el dueño de los oliuos sea obligados a los tener bien [enmatados] desde todos los Santos fasta fin de Março y los a de enmattar fasta que aian quatro años y que de los oliuos de quatro años arriua se aprecie el daño para los fieles.

Yten que qualquiera que pareicere auer Cortado o quebrado ô arrancado cepas en biñas jenas y por pesquisa de treinta dias se supiere tenga de pena por cada cepa quatro rs aplicados por quatro parttes para el concejo Justicia Dueño e denunciador y mas el daño para la parte el qual por auitar pleitos queda tassado desde aora en quatro rs e de cada braço beintte y quatro mrs y de cada pulgar diez mrs y si la guarda jurada qu eno tiene dañador pague un Real de cada cepa quebrada o arrancada e de los braços e pulgares quebrados pague la mitad de los biente y quatro o diez mrs de arriua para el dueño y no pague pena.

E de cada Yema comida pague el dañador dos ubas e de cada uba dos mrs e no hauiendo dañador la Guarda pague de cada uba un marabedi para el dueño y lo mismo sea de ubas comidas.

Yten que qualqueira Perssona que pareciere lleuar Carga de Sarmientos de Sarmentera ajena o por pesquissa de treinta dias se supiere pague de pena mill mrs de dia e doblado de noche aplicados por quartas partes para el concejo justicia Dueño e deunciador y lo mismo se entienda de haces de Ramas y Cepas y mas pague el daño de la eredad o los trajere que es por cada Gauilla quatro marauedis teniendo dañador e no teniendolo los mrs de cada gauilla e de cara obrada asi de sequero como de regadio se quenten diez gauillas y esse daño sea para el Dueño.

Yten que qualquiera que fuere tomado o pareciere por pesquisa de nueve días que después de podada la viña o antes de hacer la sarmentera trajera cepas y sarmientos de las viñas ajenas, pague de pena por cada carga de cepa o de sarmientos seiscientos mrs y de cada haz tres mil de dia y doble de noche, aplicados por quartas partes para el concejo, justicia, dueño é denunciador y que 
50

Podadores que no traigan cepas.

51

Oja de viñas.

52

Cojer y plantar.

53

Segadores.

54

Acavallar

tórtolas.

55

Cazar codornices.

56

Costillar.

el haz de cepa se entienda de seis cepas o braços arriba y las cepas y sarmientos para el dueño y de seis cepas abajo tenga de pena dos rs para el concejo, dueño y denunciador por terceras partes.

Yten que ningún podador pueda traer cepas ni sarmientos de la viña que podare aunque se de las de su año de la viña so pena de cien mrs aplicados por cuartas partes para la justicia, concejo, dueño y denunciador y lo mismo se entienda de sus hijos citados o mujeres de los podadores.

Yten que cualquier persona que fuere tomado o se supiere por pesquisa de nueve días que ha cogido oja de viñas ajenas pague de pena doscientos mrs de cada vez los ciento para el concejo, justicia y denunciador y los ciento para el dueño.

Yten que cualquier persona que fuere tomado o se supiere por pesquisa de nueve días haber cogido planta de viña ajena tenga de pena çiento y ciq ${ }^{\mathrm{a}} \mathrm{mrs}$ aplicados por cuartas partes para el concejo, justicia y denunciador y mas un marauedí de cada planta para el dueño.

Yten que los segadores no puedan llevar muxeres, hija ni criados a espigar adonde se paren so pena de cien mrs por cada vez aplicados por cuartas partes para el dueño, concejo, justicia, denunciador y esto aunque sea con voluntad del amo esta pena sea para el concejo, dueño y denunciador por terceras partes y que no es para quien entre cargas so la dha pena si no está el dueño delante.

Yten que cualquiera que fuere tomado en las viñas o panes con fruto acauallando tórtolas, que pague de pena tres rs aplicados por terceras partes para el dueño, concejo y denunciador y mas el daño a la parte.

Yten que cualquiera que fuere tomado en los panes cazando codornices con redes que tenga de pena tres rrs por cada vez aplicados por terceras partes para el dueño, concejo y denunciador y mas el daño a la parte.

Yten que ninguna persona pare Costillas alguna persona para [costillar] en viña ajena teniendo frutos so pena de tres reales aplicados por terceras partes para el concejo, dueño y el denunciador y pierda las costillas para el que las tomare.

57

Yten que ningún vecino de esta villa ni de fuera de ella pueda andar con Perros de caça en las biñas. perros entre viñas ni piezas con fruto so color que anda a caza so pena de doscientos mrs por cada vez que fuese tomado el mismo sea de alguno andando a caza derribare pedregales o hiciere daño en heredades ajenas tenga la misma pena aplicada por cuartas partes para el concejo, justicia, dueño y denunciador. 
58

Mimbres.

59

Coexr yerua.

60

Ganado menudo en heredad.

61

Ganado mayr en herd con frutto.

62

Majuelos.
Yten que ninguna persona corte mimbres ajenas so pena de que pague por cada una miembre rromana de daño dos mrs para el dueño y de las donceles a maravedí y esto para el dueño y pague mas de pena la persona que fuere tomado cortándolos o que por pesquisa de nueve días se averiguare haberlas cortado cien mrs de pena de diez mimbres hasta veinte aplicadas por terceras partes para el dueño, concejo y denunciador y si fuere haz mil mrs aplicados por cuartas partes para el concejo, justicia, dueño y denunciador y si ganados las partieren paguen la mitad del daño a la parte.

Yten que cualquiera persona que entrare a coger hierba ô a cardos o melgas o pieças biñas [auares] ô otros sembrados de semillas, teniendo fruto pague de pena por cada vez cien mrs aplicados por terceras partes para el concejo, dueño y denunciador y mas el daño que fuere apreçiado por la parte.

Otrosí que en cuanto al ganado menudo que fuere tomado en cualesquiera heredades en los términos de esta villa, que de veinte cabezas arriba tenga degüello de una cabeza de dia y dos de nche y si tuviesen los cencerros tapados tengan la pena dob lada y los gandos en quien hubieren degüello se apliquen un quarto para la Justicia, otro para el dueño de la heredad en donde fuere tomado la maior parte del ganado y otra para el concejo y otra para el custiero con el despojo y veinte cabezas abajo tenga de pena cuatro mrs por cada vez aplicados por mitad para el concejo y para el custiero, mas pague el daño dela ered ${ }^{\mathrm{a}}$ a la parte.

Yten que cualquier gandado mayor q fuere tomado en viña o pieza con fruto pague de pena por la primera vez cien mrs o el doble de noche aplicados por terceras partes para el concejo, denunciador y dueño y mas pague el año q si fuere tomado segunda vez la pena doblada y si tercera sea habido por [rrebicero] y paguen la pena que quisieren cargar la Jusiticia e aiuntamiento y si fuere tomado en las viñas no teniendo fruto pague de pena veinte mrs y el doblo de noche para la Guarda que lo hallare y entiéndase por [rrevicero] siendo tomado las tres veces habiendo fruto dentro de quince días y la pena de los dichos veinte mrs sea condenado el ganado sin guarda y sea habido por Guarda andando sin dueño en el campo cerca de él.

Yten que qualquier ganado mayor o menor que pareciere haber comido majuelo que de el primera ño que fuere plantado fuese comida de cada majuelo pague el dañador tres mrs y del segundo año dos mrs y del tercero año un maravedí para el dueño, además de la pena contenida en la ordenanza antes de esta aplicada para la guarda y de tres años sea hauido por biña y el daño sea para la parte y se puede apreciar hasta el dia de Todos Santos de cada año. 
63

Pieças

sembradas.

64

Ganado menudo

en biñas cavadas

sobre rrej ${ }^{\circ} e$

llovido y

baruechos

65

Ganados que

atan en piezas

con cargs.

66

Ganado menudo

en piezas entre

cargado.

67

Ganados que comen ojas.

68

Lino.

69

Los puercos.

70

Busto de puercos.
Yten que cualquiera que pareciere haber llevado o pisado o partido cualquier pieza sembrada ora esté nacida o no, que hasta primero dia de marzo pague la simiente de aquella parte que hubiere hollado o pisado pues hasta allí no hay daño ni aprecio y en los [avares], pague la simiente de lo que estuviese pisada e aya rrebista.

Yten que cualquier ganado menudo que entras en biñas cavadas, sobre regado e llovido y cavado y en barbechos sobre llovido pague de medio real por cada obrada y el proveedor de la carnicería ocho mrs para el dueño y sobre regado se entiende dentro de cuatro días después que lloviere y que el ganado de las carnicerías no entre en las viñas en el tiempo que se lo vedare la Justicia y ayuntamiento so la pena que le fuere puesta.

Yten que nadie pueda atar ni de dia ni de noche ganados en pieças durante que en ellas estuuieren cargas de mies so pena de dos reales de dia y doblado de noche, aplicados por terceras partes para el concejo y dueño y denunciador.

Yten que cualquier ganado menudo que entrare en piezas que tengan cargas de mies de beinte cavezas arriba tenga degüello de una caveça de dia e dos de noche aplicado por quartas ptes $\mathrm{p}^{\mathrm{a}}$ pena la Just ${ }^{\mathrm{a}}$, concejo, dueño ê denunciador y el despojo $\mathrm{p}^{\mathrm{a}}$ el denunciador con el un quarto y el daño $\mathrm{p}^{\mathrm{a}}$ la pte y de beinte caveças avaxo a quattro mr para el dueño denunciador y concejo pr terceras ptes.

Yten que cualquier ganado que fuere tomado comiendo hoja en las viñas pague de pena medio real de cada cepa de todo el daño de la cepa para el dueño.

Yten que cualquier ganado que fuere tomado o por pesquisa de nueve días hallado haber pacido o pisado lino hasta primero de marzo tenga de pena por cada vez cien mrs aplicados por terceras partes para el dueño, concejo y denunciador y mas pague el daño la simiente y labores de aquello que fuere hollado y pisado y de allí adelante pague la dicha y el daño que fuere apreciado por los fieles.

Yten que los puercos que fueren tomados en pieças o en viñas con fruto o en las eras habiendo pan en ellas tengan depena por cada uno por cada vez tres reales aplicados para el concejo y dueño y denunciador por terceras y mas el daño que fuere apreciado y si los tomare segunda vez se reparta la pena entre la Justicia y concejo y dueño y denunciador por cuartas partes ésta de la segunda pena.

Yten que los puercos que echen al busto no anden por las calles después de salido con el busto hasta que vuelvan so pena de medio real por cada uno que 
fuere tomado por las calles para el concejo y denunciador por mitad.

71

Cabras.

72

Gallinas.

73

Riegar biñas o

pieças ajenas.

74

Rivaços.

75

Distancia de

salçes e arboles.

76

Olivas e

aceitunas.

77

Piedras en los

caminos.

78

Ganados que se fuere de la Dula.
Yten que las cabras que fueren tomadas en heredades cerradas o en huertas tengan de pena por cada una un real cada vez para el dueño y denunciador por mitad y mas el daño para el dueño.

Yten que cualquiera que tomara o viere en su huerta o viña o pieza con fruto gallinas por cada una de ellas pague al dueño por cada vez cuatro mrs y esta pena pague el dueño del corral de las tales gallinas. Y si no las vieren entrar en el corral el dueño del corral $\left[{ }^{\bullet}\right]$ y si el dueño de la heredad las metiere por $\left[{ }^{\bullet}\right]$

Yten que el que regare viñas ajenas cavadas pague al dueño un real de cada obrada que el regare de cada fanega de pieza baruechada que regare cien mrs y de aí avajo al respecto.

Yten que el que derribare ribazo axeno entre heredades pague al dueño del tal ribazo el daño y mas pague de pena trescientos mrs aplicados por mitad para el dueño y para el concejo y mas que el dueño lo puede deshacer a costa del que lo derribare.

Yten que ninguno pueda poner salçes a ocho pies de heredad ajena so pena de que los pueda cortar el tal dueño de la heredad sin licencia del que los puso, con que primero averigue que están dentro de los ocho pies y lo mismo se entienda en arboles y viñas y piezas.

Yten que qualquier persona que fuere allado o por pesquissa auido auer cojido oliuas ô acitunas en oliuos ajenos tenga de pena mil mrs aplicados por quartas partes para la Just ${ }^{\mathrm{a}}$ concejo ê dueño e denunciador ahora sea antes o después de hauer cojido los oliuos.

Yten que ningún vecino desta uilla ni de fuera de ella no echen piedras de sus heredades a los caminos so pena de dos rr por cada bez que las echaren para el concejo ê denunciador por mitad y que acosta deel que la echo las buelban a echar en su herd ${ }^{\mathrm{a}}$.

Yten que si pareciere que algún ganado se ba de la dula al que lo guarda por no poderlo tener o de casa de algún vecino esta uilla se soltare o alguno se le fuere que no el tal vecino o ganadero fuere tras de el o prouare que se le solto sin hauer en ello malicia que este tal no sea obligado a pagar mas pena de el daño que hiziere.

\footnotetext{
- Ilegible en el texto.

- Ilegible en el texto.
} 
79

Agua para los campos.

80

Arroyos e

frontales.

81

Tender trapos en uiñas axenas lo mismo en pieças sembradas.

82

Que manifiesten los custieros al

Rexr.

83

Cabañas e moços de custieros.

84

El daño que

hicieren los

custieros.

85

Lauores de heredades.
Yten que ninguna persona sea ossado a echar agua para regar por los caminos so pena de cien mrs por cada bez aplicados para el concejo ê denunciador por mitad y que el agua de los caminos no se entienda si saliere de alguna hered ${ }^{\mathrm{a}} \mathrm{q}$ se rregare.

Yten que todos los vecinos desta villa sean obligados en cada un año fasta el dia de San Andres de limpiar los arroyos È frontales que tuvieren en su heredad so pena de que por cada $b$ ara que dejaren de limpiar paguen o dos mrs de el barear ó quatro mrs de limpiar y que la dha pena sea para el arrendador y no lohaceidno sea para el concejo y los prouissores sean obligados a los limpiar a costa del concejo y se entienda que son frontales todos los arroyos que dieren por ellos regadíos unos a otros.

Yten que qualquiera que tendiere trapos en biñas ajenas sobre las cepas por cada bez tenga un rl de pena por mitad para el concejo arrendador é denunciador no hauiendo arrendador.

Yten que ningún Custiero pueda lleuar pena sin la hauer manifestado al pror Maior so pena de pagar con el quatro tanto y que los custieros sean obligados a hacer las manifestaciones al procurador los sauados de cada semana so pena de ducientos mrs pro cada bez que lo dejaren de açer aplicados por mitad para el concejo e justicia.

Yten que los custieros sean obligados a tener sus Cauañas echas en su pago cada uno para el dia de nrâ señora de Agostto de cada un año y que desde el dho dia fasta el de San Miguel de Septiembre tenga los moços los qs bengan a jurar ante la Justicia é procurador maior so pena de que sino tuviesen echa la cauaña e tomado moço paguen de pena ducientos mrs para el concejo y que el procurador maior a su costa mande haçer la cauaña y que en todo el dho tiempo duerma la guarda en la cauaña de noche so pena de cien mrs para el dho concejo y que el pror maior les bissite las cassas.

Yten que si el custiero o su mux o hijos ó criados ó compañeros é sus ganados hiçoeren el daño que sean obligados a pagarlo cocn el quatro tanto y coto doblado aplicado por quartas partes para el concexo Justicia é dueño é denunciador.

Yten que los que tomaren biñas a rrentta ó a medios ó a estaxos o a labrar tengan de pena por cada obrada que dejaren de cauar dos rs y por edrar un rreal de cada obrada y del Escardar medio rrl de cada obrada y quelos escarden fasta el dia de Sn Juan de Junio y los cauen en todo mayo y las yedren en todo Junio y 
que asi mismo pierdan el fruto de la tal obrada que dejaren de cauar y todo el dho daño y pena sea para el dueño de la Heredad y que paguen de cada obrada que dejasen de [escarcuñar] veinte y cinco mrs y que paden en todo el mes de março so pena de un rl por cada obrada que dejaren de podar para el dueño pasado s los dos términos pueda e dueño de ha herd hacer dar las lauores $\mathrm{q}$ dejaren de dar a la tal herd que tuvieren dada arrenta o amedias ó a estajo.

86

Sobre el cortar en la dehesa los Vecinos.

87

Lo mismo los no Vecinos.

88

Pasto de la dehessa a los bez ${ }^{\circ}$.

89

Cortar en los montes de esta uilla y Daroca.

90

Los monttes desta $u^{a}$ Sottes y Daroca.
Yten que quanto a la dehessa de la verde y baqueriças que es propio en particular desta uilla que qualquier becino ò morador de ella é sus arrauales que por cada un pie de Ancina o rrobre que cortare o sacare de ella pague de pena trecientos mrs e por cada rrama cinquenta mrs é por cada carga de leña dos mil mrs e de cada az ducientos mrs aplicados las dos terceras partes para el concexo e la otra pare el denunciador y si fuere tomado segudna bez aia la Justicia la tercera partee y otra tercera el concejo y otra tercera el denunciador y esto sea de la segunda pena y se lleuen y executten las dhas penas no auiendo dado licencia la Just ${ }^{\mathrm{a}}$ ô rreximito porque hauiendola dado no tenga pena.

Yten que si alguno no becino desta uilla fuere tomado cortando en la dha dehessa de la verde e baqueriás que no sea morador en esta uilla tenga de pena por cada pie que cortare tres mil mrs é de cada rrama mil e quineintos mrs e de cada carga tres mil mrs é de cada az mil mrs aplicados por tterceras partes para el concejo é justicia é denunciador.

Yten que qualquier Vecino de esta uilla que fuera de los tres meses henero febrero y marzo entrare con ganado menudo a paçer en la dha dehessa de la berde y baqueriças sin licencia d ela Justicia y rreximto tenga de pena de veinte caueças arriua degüello de una caueça de dia ê doblado de noche aplicado por terceras partes para el concejo Just y denunciador é de allí abajo un rrl de pena para la guarda.

Yten que qualquier extranjero desta uilla que no fuere morador en ella que entrare a pacer la yerua de la dha deessa de la uerde é baqueriças con ganado menudo é por cada bez tengan de pena de veinte cauecas arriua tres mil mrs y seis mil de noche si treajere cencerros atapados la pena doblada la qual pena sea para la justicia concejo e denunciador por terceras partes de ay abajo a diez mrs por cada caueá para la guarda concejo e si fuere ganado maior pague de pena ducientos mrs por cada caueça que fuere tomada dentro aplicados según de suso.

Yten en quanto a los monttes de Moncaluillo e otros desta dha uilla que son propios de ella e de lugar de Daroca que qualquier becino destauilla e de fuera de ella u de los lugrs de su jurisdicción que por cada carga que cortaren y sacaren de los dhos monttes pague de pena dos mil mrs y de cada az ducientos mrs digo de cada az cien mrs é por cada pie de rrobre é de aya duçientos mrs e por cada rrama cinquenta mrs aplicados por terceras partes para la Just ${ }^{\mathrm{a}}$ e para la uolssa común de dha uilla é del lugar de Daroca e para el denunz . 
91

Pastos Sottes y

Daroca.

y cortar en dhos

montes.

92

Pastos de

ganados de esta

uilla Daroca é

Sottes é otros.

93

El dueño lleue el Cotto.

94

No auiendo

dañador que la

guarda pague la

mitad del daño.

95

Cauas.

96

Agua de la fuente de la Plaza.

97

Pilas é poços.
Yten que qualquiera Perssona que fuere tomado en los monttes de dehesas zerradas que esta Villa tiene en comunidad con el su lugar de Sotes cortando por pie tenga de pena por cada carga mil mrs é por cada az cien mrs e por cada pie de rrobre quatrozientos mrs e por cada pie de aya trecientos mrs e por cada rrama cienquenta mrs aplicados por terceras partes para la Just ${ }^{\mathrm{a}}$ é para la bolsa común destauilla é del dho lugr de Sottes y que la dha pena se entienda cortando contra las prematicas Rs.

Yten que qualquiera persona que fuere tomado con ganados paciendo las yeruas de los términos del lugar de Daroca é del lugar de sottes que son en comunidad con esta uilla siendo extranjero destauilla é los dhos lugs tengan de pena de veinte caueás arriua de ganado menudo dos caueças de degüello de dia y quatro de noche y traiendo los cencerros tapados la pena doblada aplicada la pena por terceras partes a la Justicia é denunciador é a la bolsa común desta Villa e de los dhos lugs e que de veinte caueças auajo tenga de pena ocho mrs para la Guarda de cada caueza si fuere en ganados maiores un rrl de cada caueça aplicados según de susso.

Yten que el dueño de qualquier heredad que el por su persona prendare en sus herds demás de el Daño pueda lleuar el coto como el custiero lo auia de lleuar si lo prendare.

Yten que en las cosas y daños que hicieren de que la Guarda jurada q no tiene dañador pague mas de la mitad de los daños que ban declarados en estas ordenanças.

Yten que los rregadores e pror maior e diputados é personas del aiuntamto desta villa puedan prendar y manifestar a personas é ganados que allaren haciendo daño en heredades monttes dehesas guertas é cerrados é que la parte $\mathrm{q}$ hauia de lleuar el denunciador sea para el concexo y si en sus heredades propias los prendaren la fal parte sea para el dueño de la tal herd ${ }^{\mathrm{a}}$.

Otrosi que ninguna persona eche tierra en las cassas ni estiércol ni en las salidas de las puertas de la uilla so pena de trezientos mrs por cada bez para obras publicas y que se saque a su costa.

Yten que auqluiera persona que pareciere auer cortado el agua de la fuente desta uilla que es la de la Plaça pague de pena por cada bez ducientos mrs este de la pressa de Vananentte a esta uilla y de allí hacia arriua seiscientos mrs aplicados por terceras partes $\mathrm{p}^{\mathrm{a}}$ la Just ${ }^{\mathrm{a}}$ concexo é denunz ${ }^{\mathrm{o}}$.

Yten que qualquiera que vaciare las pilas e poços de las fuentes desta $\mathrm{u}^{\mathrm{a}}$ pague de pena por cada bez seiscientos mrs de dia e doblado de noche aplicados 
por terceras partes para el concejo Just ${ }^{\mathrm{a}} \mathrm{y}$ denunciador.

98

Verduras.

99

Paños.

100

Tripas.

101

Arcaduces de la fuente de Auaxo.

Descubrirlos.

Sacar agua.

Torcer trapos en las fuentes.

105

Pena del q no

tuviere con que

pagar.

106

Carretas pos las calles.

107

Que manifiesten al Pror maior.
Yten que qualquiera que lauare verduras en dhas fuentes e pilas pague por cada bez medio rl para el denunciador.

Y el que lauare paños en dhas fuentes y pìlas pague un rrl por cada bez para el denunciador.

Y el que lauare tripas en dhas fuentes tenga de pena ducientos mrs aplicados por terceras pttes para el concejo justicia y denunciador.

Y si alguno abriere los arcaduces de la fuente de auajo para rregar pague de pena seiscientos mrs siendo dia é doblado de noche= y el que los descubriere para beueer pague çien mrs por cada bez.

Y si para rregar sacaren de las pilas o poços en gamellas u otra cossa pague de pena por cada bez trezientos mrs aplicados por terceras partes para el concejo Justicia y denunciador.

Yten que no puedan torcer los trapos ni sacudir el agua deellos sobre las puentes de los ríos destauilla so pena de un rreal para el concejo é denunciador por mitad.

Yten que qualquier persona q no tuviere con que pagar la pena o penas de susso contenidas salga desterrado destauilla y sus términos por medio año preciso y por la segunda bez no teniendo con que pagar estte dos oras en la argolla.

Yten que ningún becino desta uilla pueda meter carretas con cargas en ellas lo de la plaça auajo por la parte de arriua ni los de la plaça arriua por la parte de auajo sino que los que hubieren dedificar de la plaça auajo las entren por auajo y los de la plaça arriua por arriua so pena de trezientos mrs por cada bez aplicados para la Justicia concexo i denunciador por tterceras partes.

Yten los dhos Señores Just ${ }^{\mathrm{a}}$ y rreximto hordenaron y mandaron que comforme a las costumbres que se an tenido las guardas e becinos baian a manifestar y manifiestten en el Sauado de cada semana las prendas que ubieren echo al pror mario que es o fuere desta uilla el qual pueda mandar y mande sacar las prendas por las penas según de suso ban declaradas y entregarlas a los prouissores para que las bendan é agana pago á cada uno de la parte que ubiere de hauer de las dhas penas é se las escriua y ponga por cargo y rreciuo en el libro 
de la prouissoria so pena que si el procurador fuere rremisso ô neglixente en esto el aiuntamto le pueda castigar a su albedrio.

108

Que que dando prendas de la pena no aia priss $^{\circ}$.

109

Que la Just ${ }^{a}$ no lleue pte sin que este pagado dueño concejo e denunciador.

Ramas de aruoles de fruta.
Otrosi quedando llanamte los Dañadores las prendas por las prendas de susso contenidas que no se pueda hacer proceso por la Just ${ }^{\mathrm{a}}$ ni los $\mathrm{Ssn}^{\mathrm{o}} \mathrm{s}$ lleuar dros ni carçelaxe aunque contra el que fuere reuelde é no quisiere pagar ni dar prenda llanamte y psuiere contradizion se pueda hacer proceso ymformacion e preission e los $\mathrm{Ssn}^{\circ}$ s puedan lleuar dros e la Just ${ }^{\mathrm{a}} \mathrm{y}$ el algl los suyos.

Yten que la Just ${ }^{\mathrm{a}}$ no pueda lleuar la parte de pena que de suso le esta aplicada sin que primero estten pagados el concejo é partte e denunciador de sus partes.
Yten que por el daño de ramas cortadas de aruoles de fruta se pague a los dueños por la rrama de gordor de un Palmo quinientos mrs por la Rama de medio palamo trecitnos mrs e por la rrama de gordor de cauo de acha cien mrs e por la rracon de gordor de $\left[^{\bullet}\right]$ cinqta mrs e sino tuviere dañador la guarda pague la sexta partte porque lo que del que cortare tronco de aruol ésta dho arriua y sobre la pena esta dho tamuien arriua.

Las quales dhas Hordenanças los dhos señores Justicia y rreximto estando juntos en su aiuntamto según que de susso son nombrados mandaron pregonar publicamentte en la plaça publica desta villa con boz de pregonero para que venga a noticia de todos y las mandaron guardar y executar por ellas y comforme aellas las penas cotos y daños según que por ellas ban declaradas y lo firmaron de sus nombres estando por ttestigos el Lizd ${ }^{\circ}$ Diego Lopez é Sancho Gonzalez é Diego Saenz é Antonio de Naxera es ${ }^{\circ}$ e Juan de burgos becinos de la dha uilla $=$ Sebastian de Vergara $=$ Juan Barragan $=$ Miguel rroldan $=$ Martin fernz de Entrena $=$ franc $^{0}$ Gonzalez $=$ Juan de Ayala $=$ Juan de Nauajas $=$ Pedro Perez Calaorra $=$ Passo ante mi hago fee que conozco a los otorgtes Diego Vallestero=

[Pregón] = En la uilla de Nauarrete y plaça publica de ella a trece días del mes de febrero año del señor de mil é quinientos y sesenta y quatro años los dhos señores Justicia y rrejimiento hicieron apregonar y se apregonaron estos Capitulos e hordenanças arriua contenidos por boz de $\mathrm{Ju}^{\circ}$ de [huessa] pregon $^{\circ} \mathrm{ppc}^{\circ}$ el ql dho pregonero las apregono en altgas é yntelijibles voces leiendoselas yo Diego Vallestero Son $\mathrm{ppc}^{\circ}$ de la Rl Magd é del aiuntamto desta dha $\mathrm{u}^{\mathrm{a}}$ este presste e no estando prestes por ttestigos Pedro de Castrouiejo y Hernan Majuelos [^] y Hernan ballesttero y Diego de fuen Mayr e otros muchos $V^{\circ}$ s de la dha $u^{\text {a }}$ de Naut en fee de lo ql yo el dho $\mathrm{ssn}^{\circ}$ saque fui presete a leerlas e

\footnotetext{
- Ilegible en el texto.

- Espacio en blanco en el texto.
} 
acerlas e pregonar lo hice scriuir y subscriuir según y de la manera que por ante mi se hicieron pr los dhos Sres Just ${ }^{\mathrm{a}} \mathrm{y}$ rreximt $^{0}$ de dha $\mathrm{u}^{\mathrm{a}} \mathrm{y}$ se apregonaron en fee de lo qual fiçe este $\mathrm{mi}$ acostumbrado signo= que es a tal= es testimonio de Verdad Diego Vallestero=

[Not $\left.{ }^{\mathrm{a}}\right] \quad=$ En la uilla de Nauarrete a postrero dia del mes de febrero de mil é quinientos y sesenta y quatro años de pedimto de Miguel rroldan pror general de dha $\mathrm{u}^{\mathrm{a}} \mathrm{y}$ Hernando Alonsso Ssno d ela Magd Rl lei y notifique estas ordenanzas atrás conttenidas que tocan y ablan sobre los monttes y pastos desta $\mathrm{u}^{\mathrm{a}} \mathrm{y}$ lugar de Sottes y Daroca según en ellas se contiene y declara á Sebastian Martinez procurador e a Juan alientte Jurado del lugar de Daroca en sus personas y presencias en nre de todo el dho lugr de Darcoa los q dijeron q [lo oyian] y pedían tdo de dhas ordenancas testigos franc ${ }^{\circ} \mathrm{Gonz}=\mathrm{e} \mathrm{Ju} \mathrm{u}^{\circ}$ barragan é Pedro Pere $=$ becinos de dha uilla en fee de lo qual lo firme de mi nombre $=$ Fernando Asesnssio=

$\left[\right.$ Pettiz $\left.^{0}\right]=$ Illmo. señor: Miguel Roldán en nombre y como pror jeneral que soi del concejo, Justicia y rrexs desta $\mathrm{u}^{\mathrm{a}}$ de Navarrete. = Digo que por el ayuntamiento de dicha villa han hecho ordenanzas para la buena gobernación de ella a consejo de otros muchos vecinos de dicha villa que para ello fueron llamados, las cuales despues de Miradas Muy bien fueron acordadas por el ayuntamiento de dicha villa y mandadas pregonar y guardar como de los autos que sobre ello an pasado a VS ${ }^{\mathrm{a}}$ constara porque suplico en el dicho nombre sea $S$. $S^{a}$ servido de mandarlas confirmar porque así conviene al servicio de Dios y de $V^{a}$ y bien de esta república y para ello...

[Confirmación] Yo el Duque Don Manrique de Lara, a vos mi gobernador, regidores y diputados y vecinos de la mi villa de Navarrete sabed que Miguel Roldán en nombre de esa dicha villa y concejo, Justicia y regimiento de ella presento ante mi las ordenanzas que esa dicha villa ha hecho para su buen gobierno e regimiento y me pidió que atento que las dichas ordenanzas eran buenas justas y útiles y provechosas a la dicha villa, las mandase confirmar y confirmarse para que fuesen guardadas y por mi vistas y parecerme ser buenas y justas por la presente confirmo y apruebo dichas ordenanzas y mando que sean guardadas y ejecutadas de aquí adelante y en esa villa y sus términos y jurisdicción con tanto que por esta dicha confirmación no se ha visto perjudicarme en cosa alguna ni a mí ni a mis sucesores. Hecho en la villa de Madrid a viente y cuatro de abril de mil y quinientos y sesenta y cuatro años. El Duque Conde. Por mandado del Duque mi señor, Geronimo Lopez Hurtd ${ }^{\circ}$. Fecho sacado rejido y concertado fue este dicho trestado en estas veynte y tres fojas de pliego de papel.

[Poder] Sepan cuantos esta carta de poder y procuración vieren como nosotros el concejo, justicia y regimiento de la villa de Navarrete estando juntos en nuestro ayuntamiento como lo tenemos de uso y de costumbre de nos ayuntar para las cosas cumplideras al bien y procomún de la dicha villa y vecinos de ella especialmente en el dicho ayuntamiento Sebastián de Vergara, gobernador en la dicha villa y su tierra y jurisdicción y Juan Barragan, regidor de dicha villa y concejo de ella y Miguel Roldán, procurador general de la dicha villa y Francisco González y Juan de Ayala y Martín 
Fernández de Navarrete y Pedro Pérez Calahorra, Martín Fernández de Entrena e Juan de Navajas, diputados de dicha $\left[{ }^{\diamond}\right]$ Estando así juntos que representamos al dicho concejo y vecinos Villa otorgamos y conocemos por esta presente carta quedamos por nos mismos y en nombre del dicho concejo y vecinos $\left[{ }^{\diamond}\right]$ de ella todo nrô poder complido libre llenero bastante según que lo havemos o tenemos e según que mejor y más cumplidamente lo podemos dar y otorgar y puede valer de derecho por nos mismos y en nombre de dicho ayuntamiento a vos Miguel Roldán y Martín Fernández y Pedro Pérez de Calahorra y Juan de Ayala, vecinos de la dicha villa que presentes estais generalmente para en todos nuestros pleitos y causas movidos y por mover de cualquier calidad y condición que sean asi civiles como criminales y para que acerca de los dichos nuestros pleitos y causas que habemos y tenemos en nombre de dicho concejo y villa y lo a ello anejo y dependiente y podáis parecer y parezcais ante la real Magestad y ante todos cualesquier juez y justicias de la real Magestad y ante ellos y cualquiera de ellos podáis hacer y hagais todos los pedimentos y requerimientos y protestaciones y poner demandas contra cualesquier concejos y otras cualesquier personas que sean de cualquier calidad condición que sean responder y demandar o demandas que a la dicha villa y ayuntamiento se pusieren y hacer y hagáis todos otros autos y diligencias que nos y cada uno de nos in solidum en nombre de la dicha villa podriamos hacer y hacer podríamos a ello presentes siendo y para que hagais todos y cualesquier requerimientos o requerimientos y protestaciones a todos y cualesquier personas de cualquier calidad y condición que sean que se requiera ni a presencia personal y mas especial mandando y en nuestro nombre podáis hacer y sustituir un procurador dos o mas cada uno de vos e in solidum que si es necesario relevación vos relevamos de toda carga de Satisf ${ }^{\circ}$ fiadura y caucion, y en nuestra anima y del dicho conejo y vecinos de la dicha villa podéis hacer y hagáis todos y cualesquier juramentos o juramentos así de calunia como decisorio de verdad decir y dejarlos y defenderlos en las tal partes y en prueba de los dichos nuestros pleitos podáis presentar testigos y escrituras y otra cualquier manera de prueba y ver jurar conocer los testigos que las tales partes presentares tasarlos y contradecirlos asi en dichos como en personas y provarlas tales tachas e [ofebtos] Concluir y cerrar procesos e oir sentencia ó sentencias asi interlocutorias como difinitiuas con sentir en las que por nos o nos se dieren apelar é suplicar de las en contrario y sacar costas y darlas a ejecutar y cobreislas y dar cartas de pago y finiquito de ellas y nos obligamos cada uno de nos ynsolidum y en nombre del dho concexo que abremos por bueno [rrato grato] é estable e valedero todo qto por bos é vuestros substituidos fuere echo actuado para ahora e todo tiempo cumplido poder como nos e cada uno de nos lo auemos y tenemos por tal y asse mismo damos e otorgamos en nombre del dho concexo é becinos de ella con todas sus incidencias dependiencias anexsidades conexsidades e con libe é general administración so la clausula del dro que es dho en latin judicum sin judicarum solui con todas sus clausulas acostumbradas y los dros en tal casso quieren y disponen que el mismo poder que nos é cada uno de nos ynsolidum tenemos como dhos es en nombre del dho concexo e se mismo damos é otorgamos jeneralmentte a bosotyros los hos Miguel rroldan Martin fernandez de Entrena é Pedro Perez Calaorra y Juan de Ayala é cada uno de bos ynsolidum que es fho y otorgado en la uilla de Nauarrette a quatro días del mes de Noure de el año de mil e quinientos sesenta y

\footnotetext{
$\diamond$ Página deteriorada.

$\diamond$ Página deteriorada.
} 
quatro años e lo firmaron de sus nombres ttestigos Juan de Burgos el Lizdo Diego Lopez Martin Marques becinos de la dha uilla= Seuastian Bergara= Iban Varragan= Martin fernz Nauarretee $=$ Migl Roldan $=$ franc ${ }^{\circ}$ Gonzalez $=$ Juan de Nauajas $=$ Juan de Ayala $=$ Martin ferz de Entrena $=$ Pedro Perez Calaorra $=$ Passo ante mi y hago fee que conozco a los Res otorgtes Diego Vallestero= e yo Diego Ballestero $\mathrm{snn}^{\circ} \mathrm{ppc}^{\mathrm{o}}$ de la Magd Rl que presste fui en uno con los dhos testityos de el rrex $^{0}$ que en mi poder queda todo lo susodho hiçe scriuir y los escriui en fee de lo qual hiçe mi acostumbrado signo que es tal= En testimonio de lo qual Ballestero=. 